\title{
LA-UR- $98-4610$
}
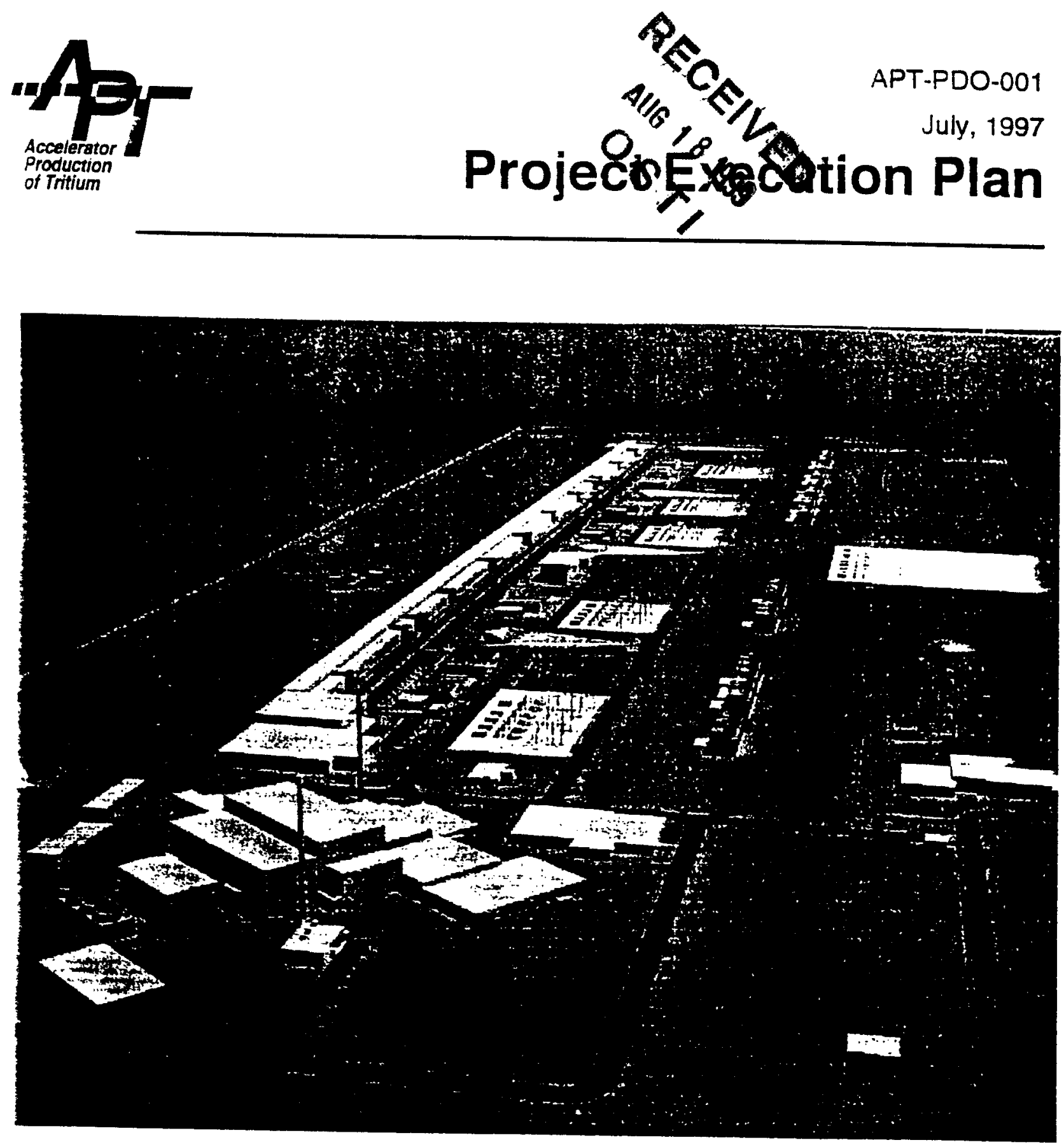

Los Alamos National Laboratory, Burns \& Roe Enterprises Inc., General Atomics, Westinghouse Savannah River Company, Brookhaven National Laboratory, Lawrence Livermore National Laboratory, Sandia National Laboratories

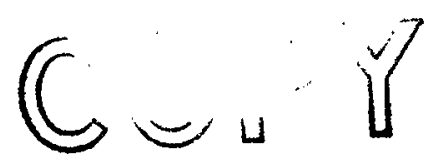




\section{DISCLAIMER}

This report was prepared as an account of work sponsored by an agency of the United States Government. Neither the United States Government nor any agency thereof, nor any of their employees, make any warranty, express or implied, or assumes any legal liability or responsibility for the accuracy, completeness, or usefulness of any information, apparatus, product, or process disclosed, or represents that its use would not infringe privately owned rights. Reference herein to any specific commercial product, process, or service by trade name, trademark, manufacturer, or otherwise does not necessarily constitute or imply its endorsement, recommendation, or favoring by the United States Government or any agency thereof. The views and opinions of authors expressed herein do not necessarily state or reflect those of the United States Government or any agency thereof. 


\section{DISCLAIMER}

Portions of this document may be illegible in electronic image products. Images are produced from the best available original document. 


\section{Table of Contents}

1 ACCELERATOR PRODUCTION OF TRITIUM PROJECT MISSION AND OBJECTIVES .. 1

1.1 Introduction 1

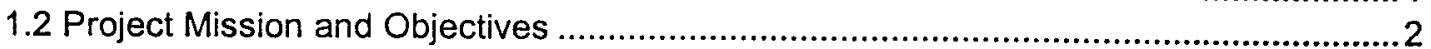

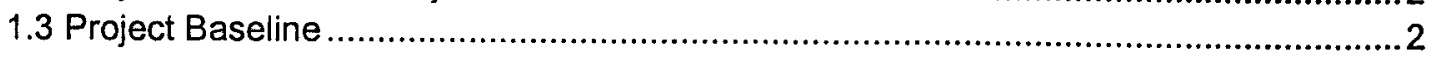

2 ACCELERATOR PRODUCTION OF TRITIUM PROJECT DESCRIPTION .........................5

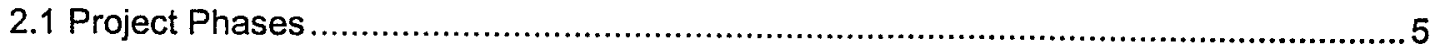

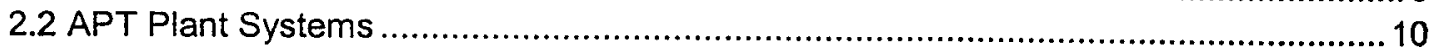

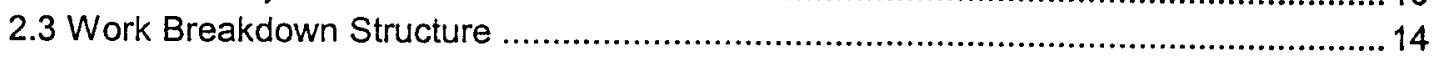

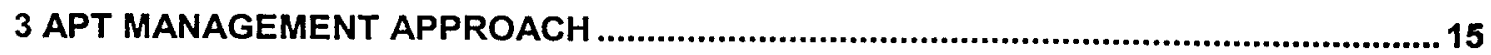

3.1 Department Of Energy Direction and Management ............................................... 16

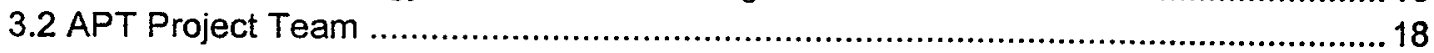

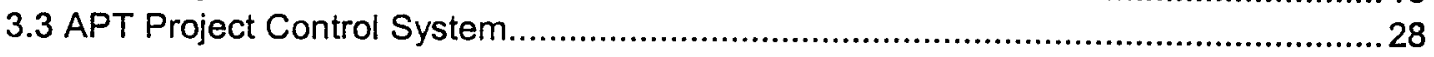

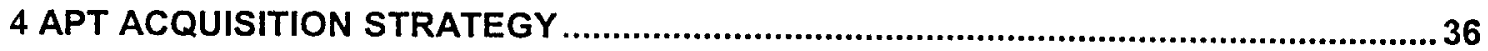

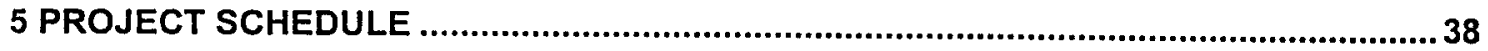

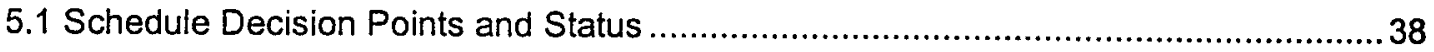

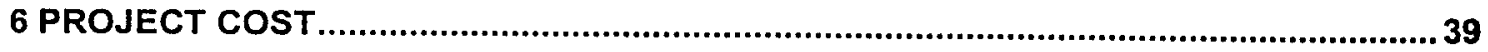

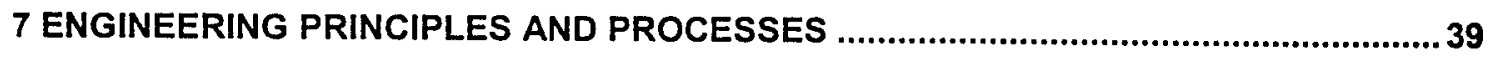

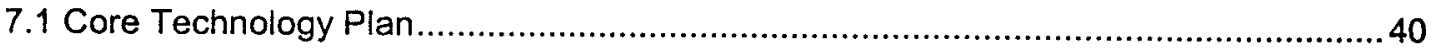

7.2 Systems Engineering Management................................................................ 40

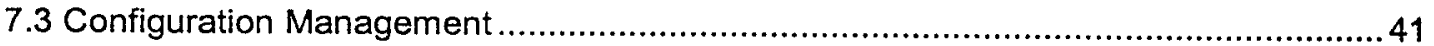

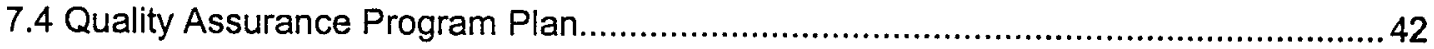

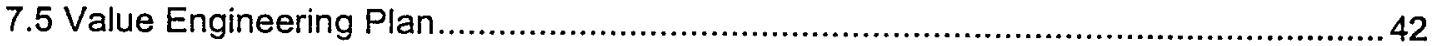

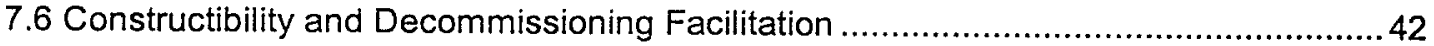

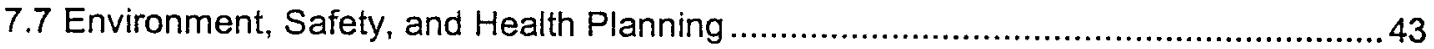

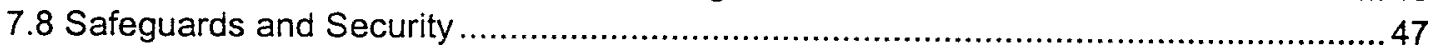

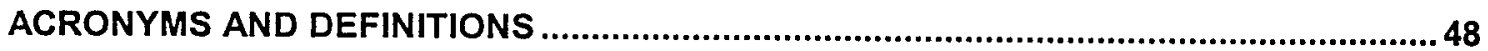

\section{LIST OF TABLES AND FIGURES}

Figure $1 \quad$ APT Project 4

Figure $2 \quad$ Work Breakdown Structure Level $2 \quad 15$

$\begin{array}{lll}\text { Figure } 3 & \text { Apt Management Team } & 20\end{array}$

$\begin{array}{lll}\text { Figure } 4 & \text { APT Project Director's } & 22\end{array}$

Figure $5 \quad$ Systems Engineering $\quad 41$

$\begin{array}{llr}\text { Table } 1 & \text { APT Team Member Roles and } & 19\end{array}$

Table 2 Project Baseline Scope, Cost and Schedule Change Control Authorities.... 29

Table $3 \quad$ Required Project Controls 33

$\begin{array}{lll}\text { Table } 4 & \text { Total Program Cost } & 39\end{array}$ 
Management Plan, Rev. 0

Donald N. Fultonberg

APT PPO Configuration Management

Donald N. Grace

APT PPO Configuration Manager

Jack T. McCormack

APT PPO Project Director
Author

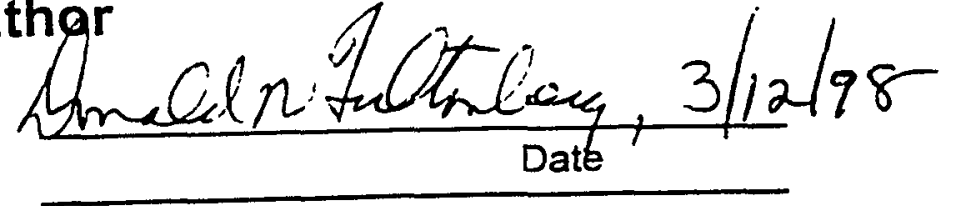

Approval

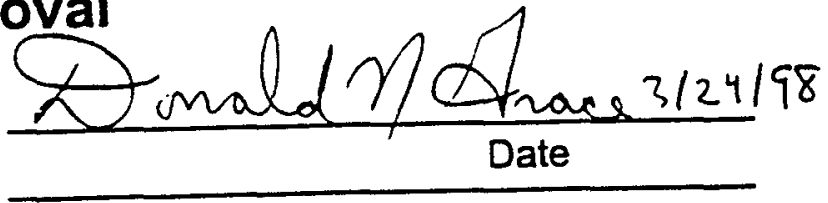

Approval

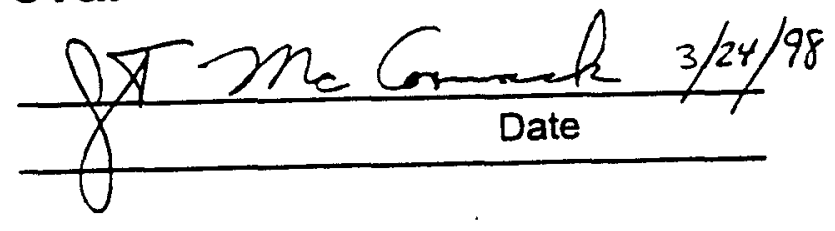

9 RELEASED

MAP 301998

APT PPO Management Plan

ii

APT Doc. No. APT-PPO-0001, Rev 0 


\section{DISCLAIMER}

This document was prepared by Burns and Roe Enterprises, Inc. and General Atomics under DOE Contract DE-AC04-96AL89607, and is intended for use solely in conjunction with the Accelerator Production of Tritium (APT) Project. The information contained herein shall not be disclosed, duplicated, or released in whole or in part for any purpose other than the APT Project without the express written consent of the US Department of Energy and Burns and Roe Enterprises, Inc./General Atomics. 
MANAGEMENT PLAN REVISION CONTROL

Prepared by:

Date:

Approved By:

APT PPO Project Director

Date:

Management Plan for Accelerator

Production of Tritium Project

APT - MP

Revision 0

PPO Configuration Manager Approval of Change

Signature

Date:

PPO Project Director Approval of Change

Signature

Date

Summary of Changes

\begin{tabular}{|l|l|l|}
\hline $\begin{array}{l}\text { Revision No. and } \\
\text { Date }\end{array}$ & $\begin{array}{l}\text { Pages Affected by the } \\
\text { Change }\end{array}$ & Reason \\
\hline & & \\
\hline & & \\
\hline & & \\
\hline & & \\
\hline & & \\
\hline & & \\
\hline & & \\
\hline & & \\
\hline
\end{tabular}




\section{Accelerator Production of Tritium Project Mission and Objectives}

\subsection{Introduction}

Tritium is an essential ingredient in US nuclear weapons. Because tritium has a radioactive half-life of 12.3 years, it must be replenished periodically for weapons to operate as designed. Tritium does not occur in useful quantities in nature and must be produced in specialized facilities that use nuclear reactions to transform another element into tritium. The US has been without such a facility since 1988 , but has been able to maintain the tritium stockpile using tritium recovered from dismantled weapons. This approach cannot be sustained indefinitely. Presidential direction requires an Accelerator Production of Tritium (APT) System to come on line by fiscal year FY2007 to maintain the nation's nuclear deterrent, if APT is chosen for construction by the Department of Energy (DOE).

Until recently, the only practical approach to producing the required amount of tritium has been use of a nuclear reactor, with nuclear fission generating the neutrons that drive tritium-producing reactions. Accelerator technology offers an alternative to nuclear reactors for this mission. Energetic protons from a linear accelerator strike a tungsten and lead target producing neutrons in quantities comparable to those in reactors. This approach to neutron production avoids the use of fissile materials (uranium or plutonium), which in turn simplifies design and licensing and offers numerous safety and environmental advantages.

To meet US tritium needs, the DOE has initiated a dual track program to ensure a new tritium source. In 1998 the DOE is planning a Record of Decision to select either APT or nuclear reactor production as the primary tritium source. The APT Project Mission is to develop an Accelerator System with the capability of producing $3 \mathrm{~kg}$ per year by FY 2007. The DOE has assigned Los Alamos National Laboratory (LANL) the responsibility for leading this effort. To that end, LANL is working with Burns and Roe Enterprises, Inc. (BREI), the Prime Contractor. LANL, WSRC and other National laboratories are conducting a development program that will lead to the most cost effective design solution. Burns and Roe Enterprises, Inc., in collaboration with General Atomics (GA) and LANL, will design, build and commission the APT Plant at the Savannah River Site (SRS) near Aiken, SC. The APT Plant will be operated by the SRS Maintenance and Operations (M\&O) Contractor, currently Westinghouse 
Savannah River Company (WSRC) with long-term technology support from LANL.

\subsection{Project Mission and Objectives}

The APT Project Mission is to design and construct a tritium production facility, which can produce $3 \mathrm{~kg}$ of tritium per year and be fully operational by FY2007.

To achieve the APT Mission and to demonstrate the accelerator technology, the DOE has established five major project phases. The first phase, Conceptual Design, is complete. The second phase of the APT Project is Engineering Development and Demonstration Program (ED\&D), which includes construction and testing Low Energy Demonstration Accelerator (LEDA), a comprehensive material testing and prototyping effort which is detailed in Section 2. The ED\&D effort supports the final phases, which are design, construction and commissioning of a functional APT Plant. The summary level APT Project Objectives include the following:

- Produce $3 \mathrm{~kg}$ of tritium per year.

- Ensure a 40-year design life for the plant.

- Minimize public and worker exposure to radiological hazards and materials, non-radiological toxic hazards and materials and industrial hazards by meeting all applicable DOE orders, requirements and State and Federal regulations.

- Construct the APT using technically acceptable and cost effective methods and practices.

- Design, construct and operate the APT using methods that are environmentally sound.

\subsection{Project Baseline}

The APT Project Baseline consists of three major components: technical scope, schedule and cost. It is the responsibility of all principal project participants to develop, implement, and maintain specific baseline plans based on material contained in the Conceptual Design Report (CDR) and which conform to this Project Execution Plan (PEP) and the APT Project Controls Policy Manual.

\subsubsection{Technical Baseline}

The APT is comprised of five major areas: 
Linear Accelerator (Linac) - produces and directs an energetic proton beam to a tritium-producing Target/Blanket (T/B). This System will:

- Produce proton power to generate tritium in the T/B at a rate sufficient for the APT plant to produce $3 \mathrm{~kg}$ per year.

- Provide a design for low enough activation due to proton losses to allow hands-on maintenance of the accelerating structures.

- Provide an expanded beam power density distribution that meets the requirements of the T/B System.

- Provide the capability to turn off the proton beam quickly enough to protect equipment and personnel.

Target/Blanket - produces neutrons by proton spallation of tungsten and lead and generates tritium through the ${ }^{3} \mathrm{He}$ reaction. This System will:

- Produce tritium in the T/B, using the proton beam from the Linac, at a rate sufficient to produce $3 \mathrm{~kg}$ per year.

- Remove heat produced by the beam during operation and by decay heat during shutdown conditions.

Tritium Separation Facility (TSF) - extracts tritium from the ${ }^{3} \mathrm{He}$ and prepares it for shipment to the SRS Tritium Facility. This System will:

- Extract $3 \mathrm{~kg}$ of tritium per year.

- Recover $>99 \%$ of the tritium transported from the T/B assembly.

- Purify the tritium to a minimum of $98.6 \%$ both isotopically and chemically.

Balance Of Plant (BOP) Complex - supports the integrated operation of these systems. The BOP will:

- Provide heat removal, process control, utility services, maintenance and waste management, emergency services, safeguards and security (S\&S) and logistics services to support process related operation of the facility at a production rate of $3 \mathrm{~kg}$ per year of tritium.

Necessary Sites and Buildings - to support the operations and maintenance (O\&M) needs of the plant. These sites and buildings will:

- Provide facility structures and buildings to house all systems and components with adequate space to provide O\&M , in-service inspection and surveillance testing.

- Provide site improvements consistent with facility design to facilitate O\&M. 


\subsubsection{Schedule Baseline}

The schedule baseline includes having the APT Plant on-line and producing tritium during FY 2007. To achieve these ends, critical milestones were established with the approval of DOE Critical Decision-1 (CD-1), Approval of Mission Need, in December 1995. That action established the APT Project, authorized commencement of the Conceptual Design activities, and established SRS as the APT Plant site. It also established the following top-level schedule for critical decision milestones:

- CD-2, Approve Project Baselines, July 1997

- CD-3, Approve Start of Construction, October 1998

- CD-4, Approve Plant Acceptance, June 2007

To support the CD-3, Approve Start of Construction, in October 1998, the DOE has committed to make the technology down-select decision no later than September, 1998. At that time it will select one of the dual track concepts that will serve as the primary source for the production of tritium. The critical decision milestones and major activities are shown in Figure 1.

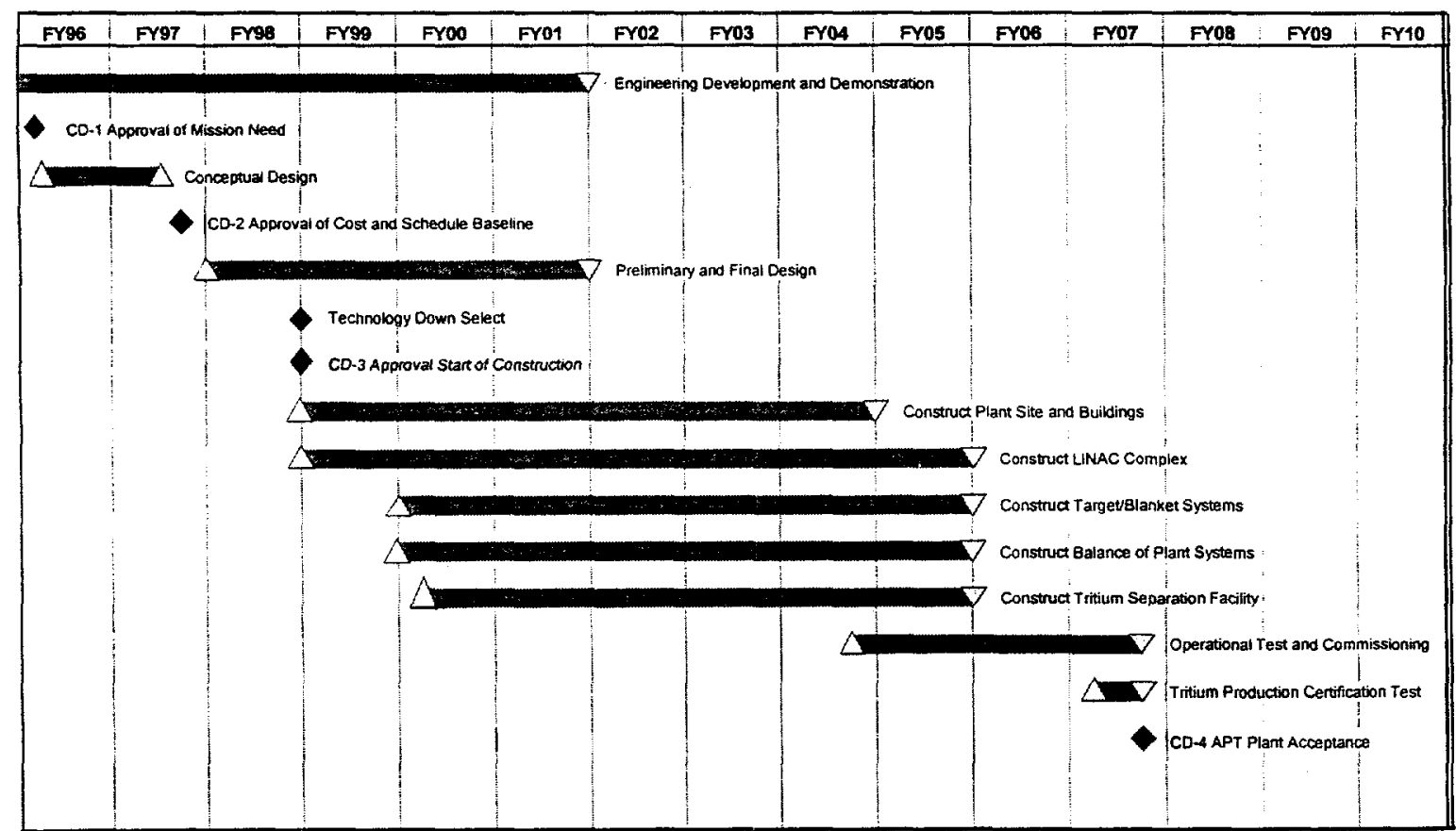

Figure 1. APT Project Summary Schedule

\subsubsection{Cost Baseline}

The Total Estimated Cost (TEC) of the APT Project, as presented in the CDR, will be baselined at the time of DOE Critical Decision-2 (CD-2). The TEC 
includes all engineering and design costs, procurement of plant equipment, construction, commissioning of the plant and all support costs necessary to achieve the plant operation. Appropriate cost contingencies will be included in the TEC baseline. The Total Project Cost (TPC) will also be baselined at CD-2 to reflect the TEC and all other project-related costs for ED\&D, Conceptual Design, Environmental Safety and Health (ES\&H) and project management.

\section{Accelerator Production of Tritium Project Description}

The APT Project activities include designing, constructing and commissioning an APT Plant at the SRS to produce tritium for the nuclear weapons stockpile complex. In support of this, an ED\&D Program is underway.

\subsection{Project Phases}

The execution of the APT Project is divided into five phases:

- Engineering Development and Demonstration (ED\&D) - Includes engineering prototyping in support of design and includes work described in Section 2.2. The work is described in detail in the APT Core Technology Plan.

- Conceptual Design - Includes defining and documenting APT Plant Systems and major equipment and establishing the preliminary Project schedule and cost estimate.

- Preliminary and Final Design (P\&FD) - Includes preparing and documenting the P\&FD of APT Plant Systems, equipment, building and structures, as well as supporting plans, implementing procedures and reporting and control systems.

- Construction - Includes constructing the site infrastructure, buildings and support systems, fabricating, procuring, installing, inspecting and installation testing of APT plan systems and equipment, and providing engineering support to construction.

- Operational Testing and Commissioning (OT\&C) - Includes commissioning and integrating the operations of individual plant systems and groups of systems and providing the initial total plant operation including a tritium production certification test. 
Given the nature of the project, several of the project phases run concurrently on different elements of work. This is shown in the APT Project summary schedule in Section 1.3.2.

\subsubsection{Engineering Development and Demonstration Phase Activities}

The Engineering, Development, \& Demonstration Phase activities are closely coordinated with the needs of the APT plant design to ensure timely availability of demonstration and prototyping data to support design, procurement, construction or plant operation. The key ED\&D activities therefore, are described in relation to the plant system they support.

- Accelerator Systems - There are two supporting programs for the Linac, LEDA and high-energy Linac structures. The LEDA will be a full-power, lowenergy prototype of the front end of the production accelerator. It will provide design confirmation and operational experience with the systems that form the accelerator front end, where developing and maintaining beam quality is most important. The LEDA Test Program will be used to:

- Confirm beam parameters, system availability and component reliability.

- Provide experimental determination of the beam halo distribution.

- Develop a commissioning plan for a continuous wave system.

- Prototype the low energy part of the APT plant accelerator.

- High-Energy Linac Structures - The High Energy Linac Structures Program will verify designs and improve the likelihood structuring will be completed on budget by fabricating and testing specific high energy prototypes.

- Target/Blanket System - The T/B System Programs encompass experiments to verify $T / B$ parameters. Key activities are:

- Verifying neutron and tritium production efficiency

- Verifying radionuclide production

- Testing prototypical beam expander magnets

- Confirming that T/B Materials will have acceptable timelines when operated at prototypic power densities in APT radiation fields.

- Tritium Separation Facility - Tritium processing activities will include evaluating and demonstrating the best technology for separating hydrogen, tritium and impurities including spallation products from the ${ }^{3} \mathrm{He}$ stream. Technologies to be considered include palladium alloy permeators, metal 
gutter beds and cryogenic trapping of the hydrogen isotopes. There will also

be an activity to measure tritium holdup/release from typical APT surfaces.

\subsubsection{Conceptual Design Phase}

During the Conceptual Design Phase, a Conceptual Design Plan was developed that guided the preparation of the Conceptual Design Report (CDR). In addition, data necessary to support the validation of capital costs was developed. The APT plant design criteria, functional performance requirements, and the design basis using the ED\&D results for the Accelerator, T/B, and TSF were established in the Conceptual Design Phase.

The CDR is a stand-alone document that allows independent review of the proposed design. The CDR supports establishment of the project baseline for scope, cost and schedule. The CDR and supporting documentation allow DOE reviewers to independently verify cost estimates.

A Systems Engineering design process has been initiated to ensure that systems and systems interfaces are identified, tracked, and documented, and that functional requirements are provided. The process will become the basis for Systems Engineering during the P\&FD Phase.

Scoping and trade studies have been performed to evaluate alternative systems and equipment designs that meet mission goals and functional performance, while minimizing capital and operating/maintenance costs and improving APT plant safety and availability. Trade studies included cost-benefit analyses when appropriate.

A design down-select process was used to provide the basis and traceability for selecting the most compatible combination of design attributes for the Conceptual Design of APT Plant Systems and equipment.

\subsubsection{Preliminary and Final Design Phase}

During the P\&FD phase, complete engineering packages that will be used to procure, build, operate, maintain, and upgrade APT Systems during the lifetime of the APT plant will be developed. The packages will include a detailed Facility Design Description (FDD), and a System Design Descriptions (SDDs) for each major system including the supporting detailed drawings, specifications, analyses, procedures and other material necessary to procure and construct the Plant. The APT plant O\&M procedures, engineering modifications and training packages will be based on the information in the FDD and SDDs. The FDD and SDDs will facilitate initial system and component design and future engineering modifications. 
Information from the CDR and the ED\&D Program will be incorporated into the P\&FD. To ensure timely availability of the ED\&D data, integrated schedules have been developed and activities will be carefully planned which will be maintained to link the needs of the two Programs. Fabrication, assembly, integration and testing will also be developed.

A formal document control and baseline design change process will be implemented. Documentation will include the basis for selecting the design choices as discussed in Section 2.3.2. Documentation will include supporting engineering studies, calculation notes, drawings and line diagrams, equipment engineering parameter lists, equipment specifications and drawings, construction drawings, construction specifications, and other supporting materials.

Trade studies will be performed as necessary to optimize functional performance and LCCs as well as reliability, availability, maintainability and inspectability (RAMI).

\subsubsection{Construction Phase}

The physical construction of the APT Plant will be accomplished during this phase. Major activities during the phase include the following:

- Constructing the Savannah River Site (SRS) APT Plant, including preparing the site and constructing all APT buildings and other site facilities.

- Obtaining appropriate Certificates of Occupancy.

- Procuring, fabricating, installing, and inspecting accelerator, T/B and TSF components, BOP Systems and equipment.

- Testing facilities, components and equipment to ensure compliance with construction drawings and specifications.

- Providing engineering support construction and preparing as-built drawings.

The Configuration Management Program will require resolving technical issues including equipment functional interfaces resulting from changes during construction and/or equipment fabrication. The issues will be resolved and documented.

\subsubsection{Operational Testing and Commissioning}

The OT\&C phase begins with the integrated plant systems start-up and testing and concludes when the plant is in full production. Operator training is included 
in this phase. The APT plant will be commissioned in stages after appropriate Operational Readiness Reviews (ORRs) are complete. Prior to accelerating the beam to the tritium production target, systems will formally be commissioned to demonstrate readiness for operation. Target/Blanket Systems and a Tritium Separation Facility will likewise be operated both without and then with the beam.

Operational test plans, training plans, and procedures developed during the construction phase will be finalized during APT plant commissioning. The plans and procedures will be the bases by which the operability of components, subsystems and systems of the integrated APT plant are verified.

In conjunction with completing the OT\&C, the project will hire and train the operating staff. Employees of the SRS M\&O Contractor will be used to operate the Plant. In preparing for OT\&C, the following will occur:

- Staged, integrated beam and if power turn-on based on the Accelerator Commissioning Plan.

- Measurements and tests for operation.

- Configuration Management information will be updated to reflect the as-commissioned state of the plant.

- Materials Surveillance Program will be established.

- Comprehensive training programs will be developed and completed.

- On-the-job training for operators and maintenance personnel will be conducted.

\subsubsection{Close-out Plan}

The close-out of the project will be accomplished after all the assigned scope is completed and the plant has been turned over to Operations. The following documents and actions will be required prior to close-out:

- Final Documented Approval for Acceptance

- Final Documented Notice of Authorization

- Documented closing of all activity codes

- Documented complete asset

- Complete close-out and elimination of any remaining funds

With these activities complete, a Close-out Statement, including a Final Cost Report, will be issued. The Project will then be listed on the project closing schedule which confirms close-out. A Close-out Plan covering the transition from project status to operating status and the closet of the Project Offices will be prepared. 


\subsubsection{Decommissioning}

A preliminary study was prepared as part of the APT Pre-Conceptual Design to gauge the effort required to Decommission the APT plant. Contamination will be removed to a level consistent with emerging NRC criteria for license termination, and the site released without radiological restrictions. The activities are described in Chapter 6 of the CDR.

Decommissioning attributes will be considered in the initial design phases of the project to enhance and facilitate any decommissioning activities that might be necessary at the end of the useful life of the facilities. Guidelines for decommissioning will be developed and factored into detailed design criteria during the P\&FD phases. Decommissioning will be considered part of the plant final design.

\subsection{APT Plant Systems}

The systems described in Sections 2.1.1 - 2.1.4 represent selections made during the Conceptual Design process. Continuing evaluations, development and demonstrations of these and in some cases, other concepts, may result in the availability of timely improvements. These will be considered as appropriate and processed for adoption in the plant as provided in Section 3.3.

\subsubsection{Accelerator System}

The Accelerator System consists of the following subsystems:

- Proton injector to develop and maintain a continuous 100-mA current.

- Radio Frequency Quadrupole to focus and accelerate the proton beam to $7 \mathrm{MeV}$ (kinetic energy).

- Coupled-cavity drift-tube Linac to increase proton beam energy to 100 $\mathrm{MeV}$.

- Coupled-cavity Linac to accelerate the proton beam to $217 \mathrm{MeV}$.

- Superconducting Linac to accelerate the proton beam to its final energy of $1700 \mathrm{MeV}$.

- High-Energy Beam Transport to direct the beam to the T/B facility beam expander. 


\subsubsection{Target/Blanket System}

The Accelerator System provides a proton beam which is expanded and directed to a T/B assembly. The T/B assembly consists of a tungsten neutron target surrounded by a blanket in which additional neutrons are produced in lead. The neutrons are slowed by collisions in the lead and in light-water and are subsequently captured in ${ }^{3} \mathrm{He}$ to produce tritium.

A modular design is used in the T/B which incorporates a beam entrance window which is centrally located tungsten neutron source module surrounded by blanket and reflector modules. All modules reside in a cavity maintained at rough vacuum. Existing technology is used in the modular T/B design. $A$ replaceable beam entrance window and modular proton inserts have also been successfully demonstrated with proton densities similar in magnitude to those present in the APT Plant. The APT modular design provides a replaceable T/B assembly that will meet the tritium production requirement while maintaining a high degree of safety and reliability.

The beam entrances window, a double-walled inconel structure, is the interface between the accelerator and the T/B cavity and separates the high vacuum of the accelerator from the low vacuum of the T/B cavity. The proton beam from the accelerator is expanded and passed through the window into the T/B cavity. The heat deposited in the window structure is removed by a low-pressure lightwater coolant.

The tungsten neutron source, surrounded by lead modules, is centrally located within the T/B cavity. The proton beam strikes inconel tungsten rods mounted in stainless steel tubes and produces neutrons and high-energy particles through nuclear spallation. In spallation, neutrons and other subatomic particles are ejected from the tungsten nucleus as a result of bombardment by the high energy protons. Neutron source cooling tubes are connected to a manifold consisting of inlet and outlet pipes through which circulates a coolant flow of heavy water at moderate pressure. The surrounding light-water cooled lead modules provide an additional source of neutrons. Helium- $3\left({ }^{3} \mathrm{He}\right)$ gas circulating within aluminum tubing in the lead captures neutrons to produce tritium and hydrogen through the ${ }^{3} \mathrm{He}(\mathrm{N}, \mathrm{T}) \mathrm{H}$.

Blanket reflector modules surround the blanket lead modules. These are similar in design to the blanket lead modules except that light water replaces the lead. Neutrons leaking into this region are reflected by the light water thereby providing an increase in tritium production. 


\subsubsection{Tritium Separation Facility}

The TSF operates by extracting tritium from a tritium, hydrogen and ${ }^{3} \mathrm{He}$ mixture returned from the T/B System in a recirculating ${ }^{3} \mathrm{He}$ loop. The ${ }^{3} \mathrm{He}$, hydrogen and tritium mixture also contains impurities such as water, methane, ammonia and small quantities of radioactive materials. Hydrogen isotopes are separated from the ${ }^{3} \mathrm{He}$ and sent to an Isotope Separation System where the tritium is separated from hydrogen. The ${ }^{3} \mathrm{He}$ is purified and recycled to the T/B assembly. Technologies for tritium and ${ }^{3} \mathrm{He}$ handling and purification have been developed and are in use at both LANL and SRS. The ED\&D Program providing the technical basis for extending current technologies to APT conditions.

The hydrogen isotopes are separated from the ${ }^{3} \mathrm{He}$ by permeation through a heated palladium-silver alloy membrane. The ${ }^{3} \mathrm{He}$, any impurities and any remaining hydrogen isotopes are sent to a molecular sieve bed which typically operates at room temperature to remove impurities. The ${ }^{3} \mathrm{He}$ exiting the bed is recycled to the T/B assembly.

The separated tritium (including hydrogen isotope) stream, free of impurities, is then pumped to the Isotope Separation System where the tritium is separated from the hydrogen. The separation of tritium from hydrogen is based on the differences in boiling points of the two isotopes.

\subsubsection{Balance of Plant Systems}

The BOP Systems support the integrated operation of the accelerator, T/B, TSF and provide the facility buildings that house them. The BOP System designs are driven by the required electric power input, the generated waste heat to be removed throughout each facility and the need to handle radioactive materials remotely. There are three major BOP Systems:

Plant Cooling Systems - A number of components of the APT plant require cooling to remove the waste heat generated during normal operation and during shutdown. The major components requiring cooling are:

- Accelerator radio frequency structures and magnets

- Klystron power supplies

- High-energy beam transport magnets

- Tungsten target, moderator window and shield for the ${ }^{3} \mathrm{He}$ target

- Neutron source, blanket, window and shield for the target system

- Beamstop

- Spent T/B assemblies

- Neutron traps

- Intermediate energy beam dumps 
Power Supply System - The total APT electric power requirement of approximately 486 Megawatts (MW), consists of two main loads: 1.) 377 Megawatts Electrical (MWe) for the accelerator, T/B assembly and the TSF; and, 2.) $109 \mathrm{MWe}$ for the BOP components.

High voltage power lines from the switchyard distribute power to multiple substations along the length of the APT. Transformers and switchgear at the substations reduce voltage and provide power to the facility components at the specified load conditions.

Other Plant Support Systems - The APT plant requires a number of other support systems typical of such plant systems used to process gases, generate heat or radioactive materials. The systems must also exhibit ease of maintenance and ensure high reliability and availability.

\subsubsection{Site and Buildings}

Buildings and site facilities will be provided as necessary to house the systems discussed in Sections 2.1.1 through 2.1.4 and to support the O\&M requirements of the plant. The facility designs are driven by the requirements of the systems housed in these structures, O\&M activities and the shielding requirements. Key features of the Site and facilities are:

- Plant Site - The proposed site is approximately 1 million square meters of land area which will be enclosed by a property protection fence with a single controlled entry point for road and rail access in close proximity to the T/B Facility. Raw water will be supplied to the plant which will be located near a raw water treatment facility. An electrical switchyard which will provide off-site power to the accelerator facility will be located in a manner facilitating maintenance by utility personnel.

- Plant Arrangement -To determine the most viable Plant arrangement, several locations and arrangements for the facility at the SRS are being evaluated. The evaluations are based on ecology, geology, hydrology, human health and engineering considerations. Important considerations are the accelerator tunnel elevation and the location of the klystron galleries. An earth berm over the accelerator tunnel will be constructed to provide shielding where it is necessary to protect the public and workers from potential radiation effects.

- Facility Structures - The structures will be designed to provide natural phenomena hazard protection for the systems and components they house. In addition, these structures will provide a barrier to prevent or mitigate the release of radioactive and hazardous material should an accident occur.

- Accelerator and High Energy Beam Transport - Both the systems are 
housed in a concrete tunnel with dirt over the top for shielding.

- Klystron Gallery - The Klystron Gallery is a steel-frame, metal-sided building that parallels the accelerator along its entire length.

- Target/Blanket - The T/B geometry and material handling needs impose requirements on shielding design. These requirements include the ability to maintain and replace target components and enough space allocation for packaging and shipping spent target material for storage and disposal. The below-grade portion of the T/B building is reinforced concrete while the above-grade is composed of a reinforced concrete targeting bay on two sides and a steel-frame, metal-sided enclosure on the other two sides of the re-targeting bay.

\subsection{Work Breakdown Structure}

The APT Work Breakdown Structure (WBS) is product oriented and reflects the logical breakdown of the work required to complete the project. Each Level 2 element represents a system and all work associated with that system. The levels of the WBS below Level 2 are established by extending the product work description to a level at which individual components can be identified and associated with a well defined piece of equipment or structure.

The APT WBS, Level 2 Summary is shown in Figure 2. It is used as a basis of establishing performance measures as discussed in Section 3.3.4. Performance Measurement and Reporting Systems are established for accruing project costs according to applicable DOE Orders and guidelines. The WBS and a. description of each of the elements is contained the CDR. 


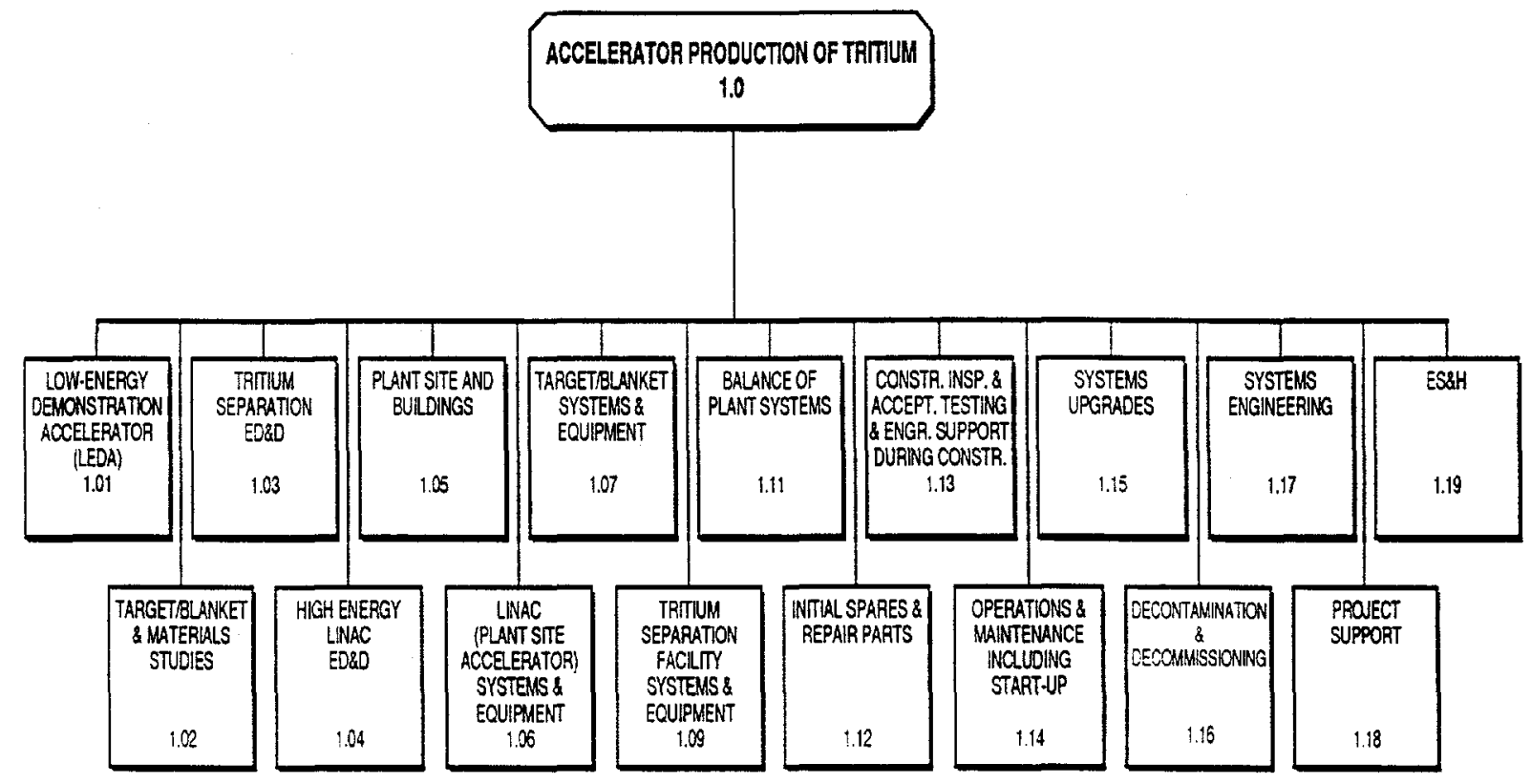

Figure 2. Work Breakdown Structure, Level 2 Summary

\section{APT Management Approach}

The APT Team responsible for managing and executing the APT Project includes:

- Department Of Energy

- Los Alamos National Laboratory

- Savannah River Site Manager \& Operator- WSRC

- Burns and Roe Enterprises, Inc., the Prime Contractor, in association with

General Atomics

- Supported by National Laboratories:

- Brookhaven National Laboratory

- Lawrence Livermore National Laboratory

- Sandia National Laboratory

- Thomas Jefferson National Accelerator Facility

- Oakridge National Laboratory

- Pacific Northwest National Laboratory

- Idaho National Engineering Laboratory

The APT Plant is designated as a strategic acquisition and as such, DOE has responsibility for overall program management and project oversight. 
Responsibility for managing and executing the Project to ensure it fulfills the established Mission and Objectives lies within the APT Project Director's Office (PDO), currently located at LANL. The PDO is comprised of contractor staff and is directed by an APT Project Director. Functionally, the APT Project Office reports to the DOE APT Program Office, DP-61 at DOE-HQ. This Section describes the roles and responsibilities of these key organizations and discusses how they interact to form an integrated team within which organizational boundaries do not impede the flow and exchange of ideas.

\subsection{Department Of Energy Direction and Management}

The DOE-HQ and field offices charged with policy, management, or oversight responsibilities are:

- Secretary of Energy, DOE-HQ: $S-1$ is the acquisition executive for strategic systems such as APT, with authority to approve Critical Decisions 1, 2, 3 and 4 for the APT Project.

- Assistant Secretary of Defense Programs, DOE-HQ: DP-1 is responsible for developing the DOE Stockpile Stewardship Program and for funding the APT Project. The Assistant Secretary is the primary interface to the Secretary of Energy, DOD, Congress and the Executive Branch.

- Tritium Project Office, DOE-HQ: DP-60 is responsible for developing the DOE dual track programs to ensure that tritium requirements are met. Responsibility for the APT Project is vested in the Office of Accelerator Production (OAP), DP-61.

- Office of Accelerator Production (OAP)DOE/HQ: DP-61 has program authority and oversight responsibility for the APT Project. It is comprised primarily of DOE staff directed by the APT Program Manager. This office performs high level policy and planning for the APT Program. It performs high level control of scope, cost, schedule milestones and performance. It provides review and oversight of all project activities and is the major interface with senior DOE officials, the DOD customer, the Administration and the Congress and other external agencies with regulatory or oversight responsibilities.

- The responsibilities of the Program Manager include:

- Establishing project policy through formal direction and approval of the Justification of Mission Need, Project Charter and the PEP.

- Securing resources, issuing DOE Project Work Authorizations, and providing formal project and technical guidance and direction to the 
APT Project Director.

- Maintaining overview of project cost, schedule, and technical performance via the reporting systems, project status review meetings, and regular communication with the APT Project Director.

- Reviewing and coordinating the approval of DOE-HQ controlled baselines and initiating critical decisions and other required reviews.

- Establishing and chairing the APT Level 1 Change Control Board (CCB) to coordinate the DOE-HQ review, assessment and action on all proposed baseline changes that are within the Level 1 approval thresholds or decision points.

- Assisting in major project actions that may exceed the purview and authority of the APT Program Director and functioning as the formal and primary point of contact for APT Project activities within DOE-HQ.

- Coordinating with other DOE-HQ Offices. Staff working with the Project Manager include satellite DOE-HQ offices as well as the DOE contacting offices, DOE-Albuquerque Operations and DOE Savannah River Operations.

- Acting as award fee determination official.

- Staff working with the Program Manager include satellite DOE/HQ Office personnel in Albuquerque and Savannah River and include the following responsibilities, liaison and oversight activities:

- Participating in contractor project team activities to maintain awareness of status and issues.

- Interpreting and advising the Program Manager about project and regulatory requirements.

- Providing an on-site interface between various APT groups.

- Acting as on-site DOE representatives to local and state agencies including coordinating site visits and reviews with the PDO.

- Providing oversight including helping the project run cost effectively and efficiently.

- Monitoring progress and tracking project performance for the Program Office.

- DOE Contracting Officer: The Contracting Officer is responsible for

- Ensuring all contractual requirements are met in a timely manner, in accordance with the project baseline.

- Advising the Program Manager on the technical, schedule and funding issues associated with the contract. 
- Ensuring contract modifications are initiated and completed for the LANL, WSRC and BREI contracts as required.

- Performing assessment and feedback regarding contract performance.

\subsection{APT Project Team}

The APT team implements, manages and executes the Project. The APT Project Director's Office is responsible for project management and execution. The Project Director reports functionally to the DOE APT Program Office and administratively to the LANL Department Laboratory Director. The APT Project execution is implemented by three major organizations with support from each other and from the other Project Team members:

- Technology Organization: directed by LANL

- APT Plant Organization: directed by PPO

- Operations Organization: directed by WSRC

The overall roles and responsibilities of the APT Project Team are shown in Table 1. The APT Project Team relationships are shown in Figure 3. 
Table 1. APT Team Member Roles and Responsibilities

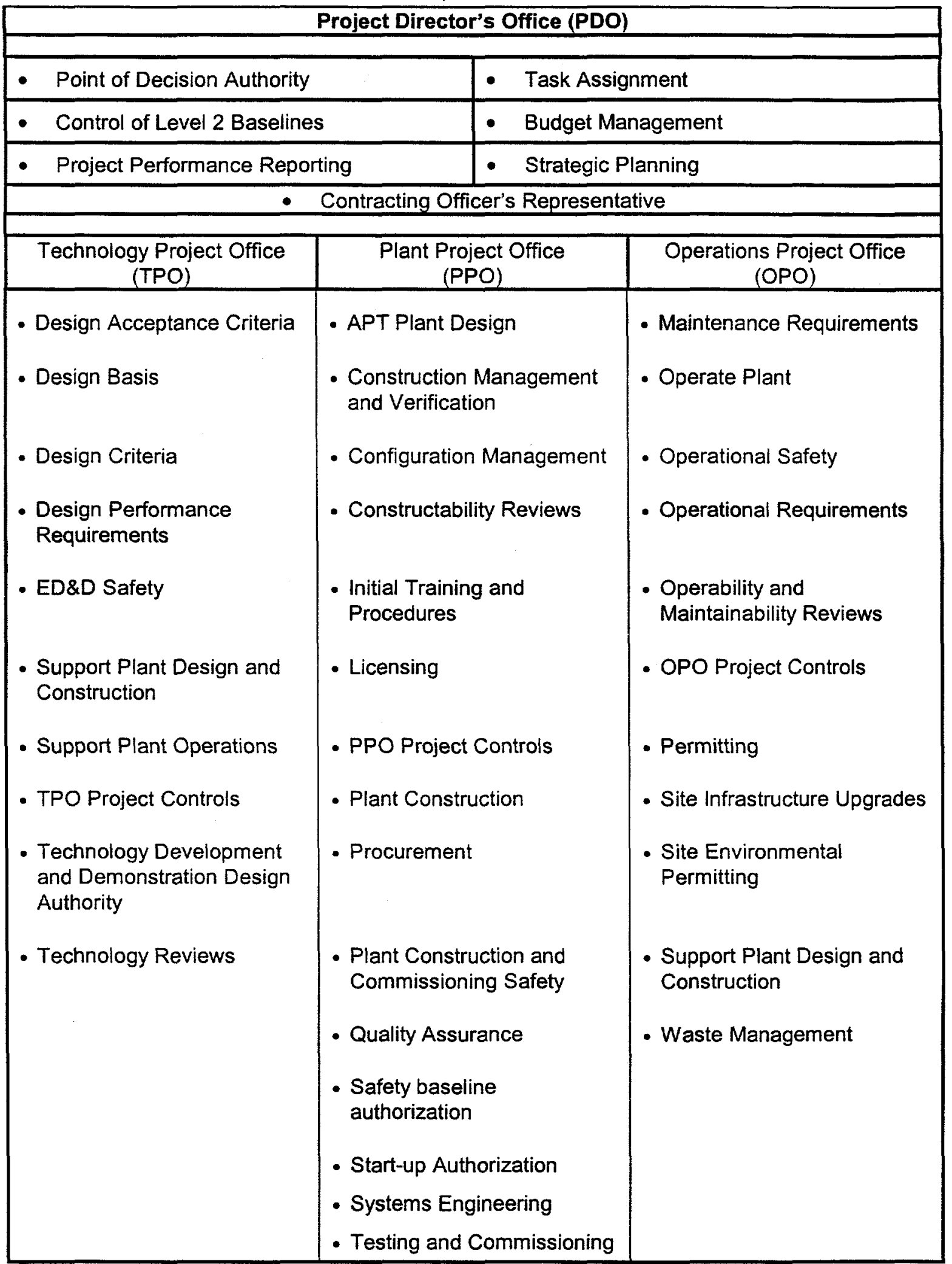




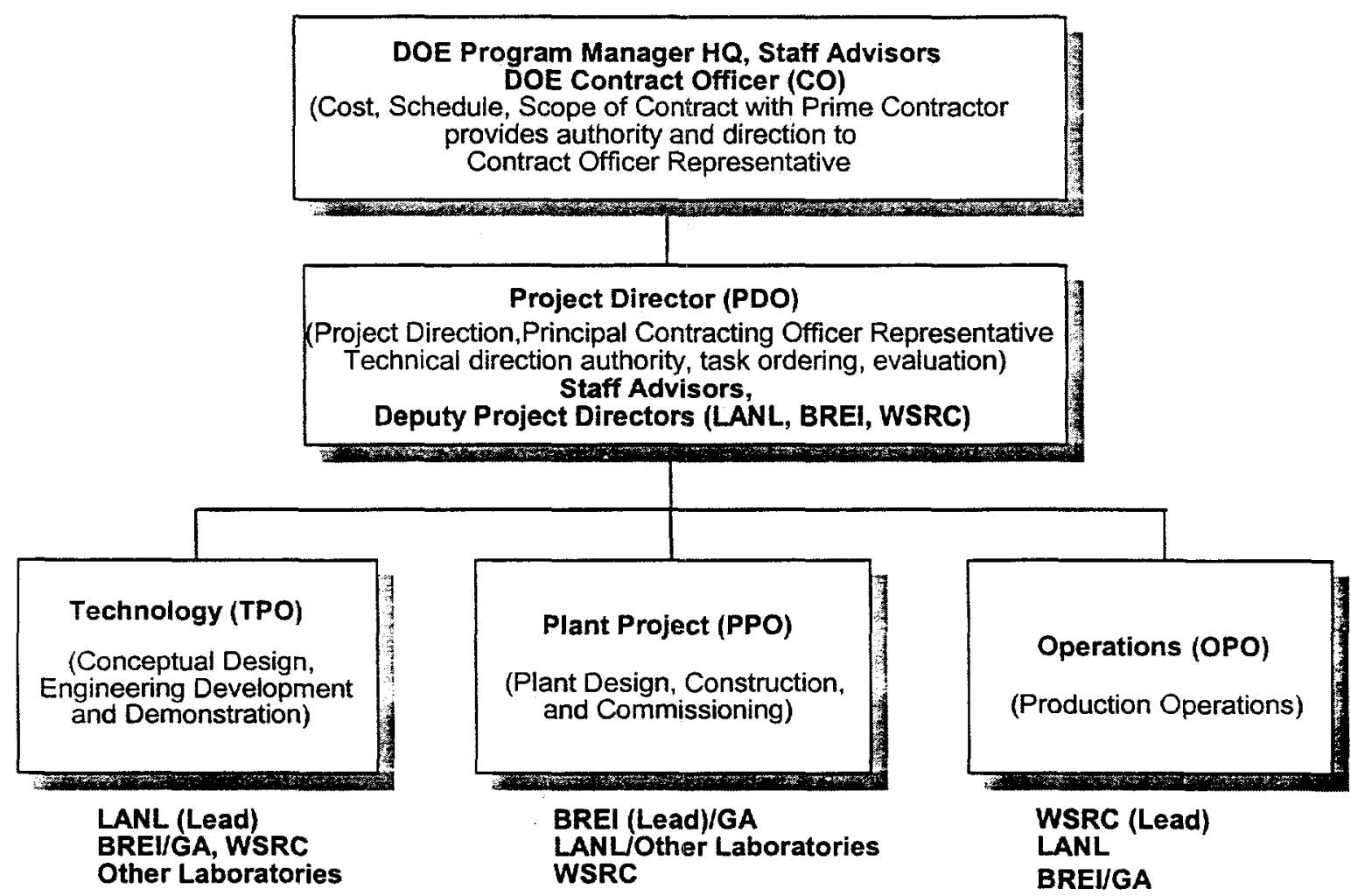

Figure 3. APT Management Team Relationships

\subsubsection{APT Project Director's Office}

The APT PDO will organize all activities necessary to manage and execute the project within the technical, cost and schedule baseline. The PDO will serve as the single point of contact with the DOE for the APT Project and will communicate with DOE program management, Congress and other stakeholder organizations regarding project performance toward meeting technical, cost and schedule objectives. The PDO will ensure that timely decisions are made to meet project objectives and will recommend solutions when appropriate to resolve issues.

The PDO is responsible for the integrating, coordinating, and overseeing all activities associated with the APT ED\&D, Technology Development, Conceptual Design, P\&FD, Plant Construction and Commissioning and Initial Tritium Operations. The APT Project Director will serve as the principal Contracting Officer's Technical Representative for the DOE.

The structure of the office of the APT PDO is shown in Figure 4. The responsibilities of the PDO include the following: 
- Execute the project to ensure activities are correctly defined and controlled.

- Monitor progress, trends and reports and implement corrective actions to resolve problems and conflicts affecting the project.

- Ensure the project baselines including technical, cost and schedule are established and maintained and routinely report project status trends and variance analyses to the DOE.

- Ensure the APT project configuration is controlled.

- Establish an APT Project Level 2 CCB to coordinate review, assessment and action on all proposed changes.

- Transmit, with recommendations to the appropriate CCB, requests for approval for all Baseline Change Proposals (BCPs) exceeding Level 2 approval thresholds.

- Provide oversight and technical direction to the PPO, the TPO and the OPO.

- Ensure the project work is conducted in accordance with applicable DOE Orders, guides, commercial best practices, institutional standards, requirements and procedures.

- Ensure the DOE assurance requirements for ES\&H, Quality Assurance and Safeguards and Security are implemented.

- Approve, with the concurrence of the Deputy Project Directors for Technology, Plant and Operations the appointment of all APT Key personnel. Such personnel are those with leadership or reporting responsibilities at WBS Level 2 or higher. 


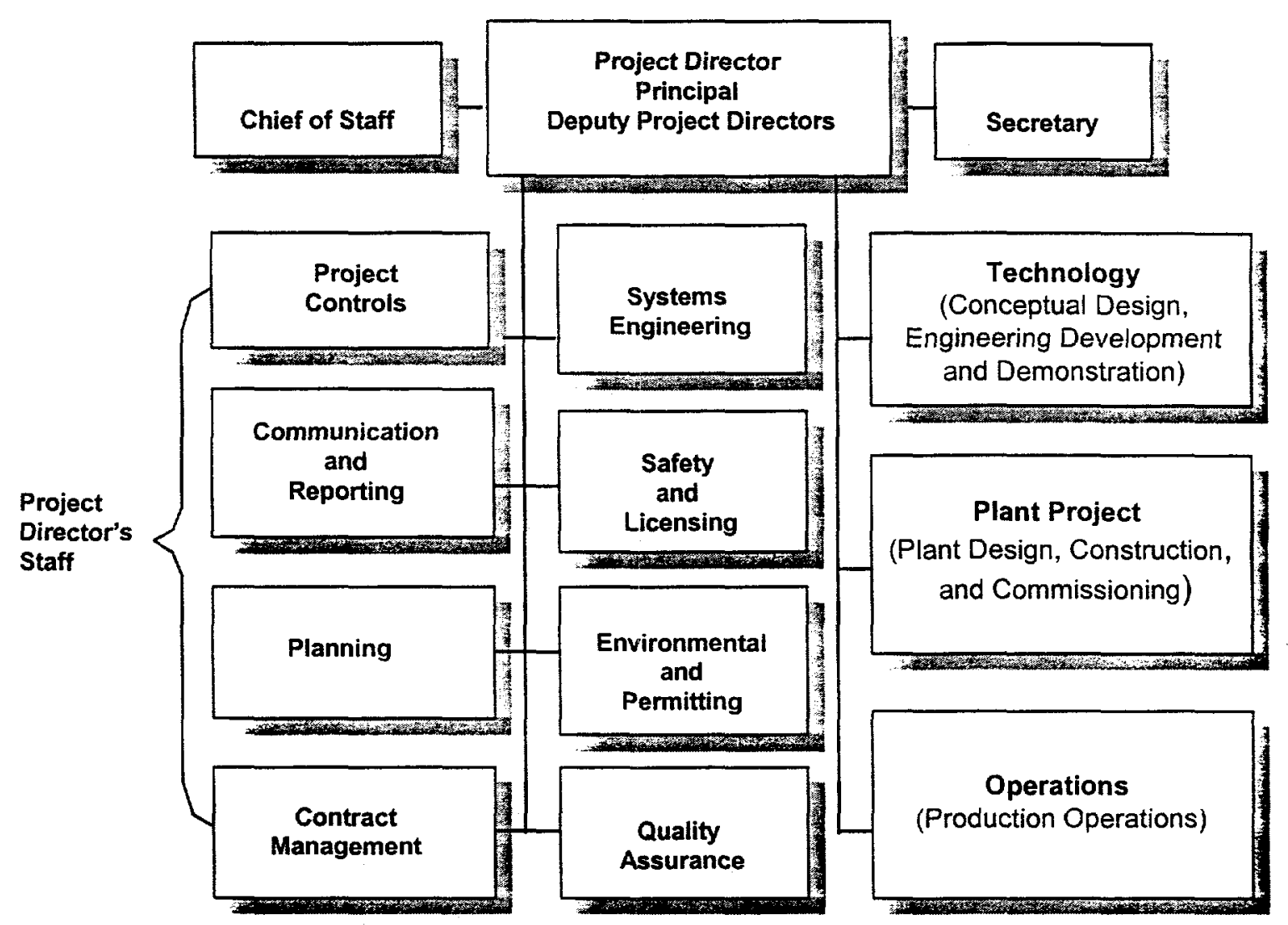

Figure 4. APT Project Director's Office

\subsubsection{Technology Project Organization, Deputy Project Director: $L A N L$}

The LANL Deputy Project Director (DPD) for Technology is one of the Deputy Directors supporting the APT PDO. The DPD oversees the TPO and reports functionally to the APT Project Director and administratively to the LANL Laboratory Director. The TPO DPD is responsible for ensuring that all APT elements have adequately demonstrated technology for safe, efficient construction, commissioning, and operation. The TPO is the Design Authority for the APT Plant and will ensure technical expertise is maintained throughout the design, construction commissioning and start-up of plant operations.

The TPO DPD will staff and direct the ED\&D activities during all phases for the APT Program. The TPO DPD will be supported by other National Laboratories as needed, as well as WSRC and BREI as described in Sections 3.2.3 and 3.2.4. The TPO DPD has lead responsibility for design and development during the ED\&D phase and had that response during the Conceptual Design Phase. The TPO will also provide long-term scientific and engineering support services to ensure success during the P\&FD, construction, commissioning, operation and decommissioning of the plant. 
The specific responsibilities of the TPO Deputy Director include the following:

- Support the APT Project Director in planning and implementing the technical program and the ED\&D activities for all phases of the project.

- Execute and manage the ED\&D Program, and ensure activities are correctly defined and controlled.

- Monitor progress and implement corrective actions for the ED\&D Program to resolve problems and conflicts affecting it.

- Control the APT project configuration during ED\&D and Conceptual Design phases.

- Transmit proposed ED\&D baseline changes exceeding the Control Level 3 approval thresholds with recommendations to the Level 2 CCB.

- Participate in the plant Level 3 CCBs and all Level 2 CCBs.

- Provide management and technical oversight of LANL subcontractor activities.

- Complete assigned project work in accordance with the applicable DOE Orders, State and local Government standards, institutional standards, requirements, and applicable procedures.

- Implement DOE assurance requirements for Environmental, Safety and Health, Quality Assurance and Safeguards and Security.

- Appoint (with the concurrence of the APT Project Director) Laboratory APT key personnel.

- Develop and maintain ED\&D project management plans and procedures consistent with this PEP.

- Develop, implement, and maintain a LANL Project Control System.

The TPO will provide resources to support PPO plant design efforts including the following:

- Physics and Engineering services based on expertise, primarily in the fields of accelerator, tritium separation, and T/B technologies. Such technologies may include physics and system analysis of the cavity/beam/ff drive interaction, beam diagnostics and other similar technologically based levels of expertise.

- Engineering services based on design development to date, including interpreting, explaining, and providing lessons learned through past experiences and design and concept evolution.

- Engineering modeling and analysis, drawing on capabilities and knowledge to augment or verify design functionality. 
During construction, design support will include review of technical change proposals. During commissioning, the TPO will assist with systems start-up and accelerator commission.

\subsubsection{Plant Project Organization, Deputy Project Director: Burns and Roe Enterprises, Inc.}

The DPD for Plant Design, Construction and Commissioning oversees the Plant Project Organization (PPO) and reports functionally to the APT Project Director and administratively to the Burns and Roe Senior Vice President, Operations. The PPO DPD is responsible for ensuring the plant is correctly designed, constructed, and commissioned to meet the DOE tritium production requirement as provided in the APT Prime Contract.

As the APT Project Prime Contractor, Burns and Roe has the contractual responsibility to design, construct and commission the APT plant by ensuring it fulfills the DOE Mission, including the tritium production requirements. The Prime Contractor also supports the APT Project Director in planning and implementing the technical program in all phases of the project.

The specific responsibilities of the PPO Deputy Director include the following:

- Execute and manage the APT Plant design, commission and construct such activities, ensuring activities are correctly defined and controlled and that the accelerator, T/B and TSF are reviewed appropriately by the TPO.

- Monitor progress and implement corrective action for the APT Plant design by resolving problems and conflicts affecting the project.

- Control project configuration during P\&FD, construction and commissioning phases.

- Establish and chair the APT Plant PPO Control Level 3 CCBs by coordinating reviews, assessments, and actions on BCPs.

- Transmit proposed APT PPO BCPs exceeding the Control Level 3 approval thresholds with recommendations to the Level 2 CCBs.

- Participate in the plant Level 3 CCBs and all Level 2 CCBs.

- Provide contract management and technical oversight of PPO subcontractor activities.

- Complete assigned project work in accordance with the applicable DOE Orders, State and local government laws and regulations, institutional standards, requirements and procedures. 
- Implement DOE assurance requirements for Environmental, Safety and Health, Quality Assurance and Safeguards and Security.

- Appoint, with the concurrence of the APT Project Director, key APT personnel.

- Develop and maintain APT Plant Project Management plans and procedures consistent with this PEP.

The overall responsibility of the PPO is to design, procure, construct and commission the APT plant which will include:

- Review and comment resolution of the draft CDR and acceptance of the final CDR with Open Items forming the basis for initiating the P\&FD.

- Develop and maintain the plant APT Project Execution Plan for the APT Project Director.

- Prepare and maintain the Configuration Management Plan, project communications, filing, document control, retrieval systems and other electronic information management systems.

- Design the Plant Systems and all site structures and facilities and integrate all aspects of the APT plant design.

- Develop and maintain the project technical and cost and schedule baselines.

- Develop and maintain all project costs and schedules.

- Develop and maintain the Plant Project Control System.

- Perform the systems engineering and integration necessary to ensure the APT performs as planned.

- Manage the construction of the plant in accordance with commercial best practices.

- Direct the commissioning of the Plant with the assistance of the LANL TPO and the OPO contractor during the OT\&C phase. This will include training the O\&M staff and testing all integrated systems.

- Collect, integrate, and report project control information to the PDO.

\subsubsection{Operations Project Office, Deputy Project Director: WSRC}

The Deputy Project Director for the Operations Project Organization (OPO) reports functionally to the APT Project Director and administratively to the WSRC Sr. Vice President for Project Operations. WSRC will be responsible for 
the long-term operation of the plant and as such, will provide input during design, construction and commissioning to ensure all operations and systems such as fire protection, S\&S, power, water, alarms, ES\&H and emergency response are compatible with existing SRS infrastructure and standards for Conduct of Operations.

The M\&O contractor at SRS, working with the TPO, PDO, and PPO, is responsible for O\&M inputs to the design and construction of the APT plant. As such, WSRC will provide support in all phases of the project. The OPO will be involved in the project from the earliest phases to ensure technology transfer and the development of accelerator skills. WSRC will support the TPO in the ED\&D and has provided support during the Conceptual Design phase of the project. It will also provide support during the technology development program to integrate accelerator technology with the conduct of O\&M. During P\&FD, WSRC will support PPO in various design aspects, including owner engineer's function, design verification and performing site infrastructure upgrades. During the construction and commissioning phase, WSRC will support, plan and prepare for the start of operations. WSRC, or its successor, will be the operator of the APT plant.

The responsibilities of the OPO Deputy Director are to:

- Manage project cost, schedule and technical elements assigned to WSRC.

- Provide WSRC input to ED\&D, design and construction activities from an O\&M standpoint.

- Provide experienced WSRC personnel, as requested, to support the ED\&D, technology or design team efforts.

- Obtain environmental regulatory permits and approvals to support construction and operations.

- Interface with external SRS regulators such as the Environmental Protection Agency (EPA), and the South Carolina Department of Health and Environmental Control (SCDHEC).

- Complete NEPA activities to support the project schedule

- Obtain required waste management services for operations of the plant

- Participate in plant Level 3 CCBs and all Level 2 CCBs.

- Provide contract management and technical oversight of SRS subcontractor activities related to site infrastructure upgrades.

- Complete assigned project work in accordance with the applicable DOE Orders, State and local government laws, institutional standards, requirements and applicable procedures. 
- Complete DOE assurance requirements for Environmental, Safety and Health, Quality Assurance and Safeguards and Security.

- Appoint, with the concurrence of the APT Project Director, key APT personnel.

- Develop and maintain O\&M plans and procedures consistent with this PEP.

- Provide infrastructure services interface to the APT site boundaries including power procurement and other site required utilities.

- Provide PPO Construction Management with site liaison support as requested such as temporary fabrication facilities, receiving, warehousing and similar others.

- Support PPO, as requested, in conduct of operations, prototype demonstrations, commissioning and start-up authorization.

- Develop and implement a program to assess and ensure operational readiness.

- Staff and develop the core competencies required to support timely start-up, commissioning and turnover of facilities for on-going O\&M.

- Ensure configuration management and QA programs are implemented to support operation of the plant.

\subsubsection{Other Project Participants Supporting National Laboratories}

The supporting National Laboratories including Los Alamos, Sandia, Brookhaven, Thomas Jefferson, Oak Ridge, Pacific Northwest and Idaho will supply staff and services to the APT Project. Senior staff may be assigned to Associate Director positions in the LANL technology project office.

Responsibilities of the Associate Directors include:

- Representing each institution on the project in terms of resource allocation, priorities and conflict resolution.

- Coordinating APT-related reviews and obtaining concurrence or approvals from each institution in support of APT Project objectives.

- Serving, as requested, as members of the Project CCB, to review proposed changes to APT baselines.

- Planning, directing, and controlling assigned project responsibilities.

- Providing input to internal and external project reviews. 
- Providing input to cost, schedule and technical reporting for each area of responsibility.

- Executing assurance responsibilities for ES\&H, QA and S\&S.

\subsection{APT Project Control System}

This section identifies the technical scope, cost, and schedule top-level baseline and the means by which each will be controlled. Section 3.3 contains descriptions of other elements of the management process including project controls and reporting and the QA Program.

A graded approach of formal, disciplined project management control systems is used to minimize overall project risk. The approach will include such items as:

- Technical scope, schedule and cost baselines

- Formal, disciplined baseline and contract change control

- Configuration management

- Reviews and assessments

- Performance measures and project reports

\subsubsection{Project Baseline}

Baselines are cost, schedule and technical definitions summarized at different levels of detail for different levels of management. The baselines are intended to ensure a project or product performs as designated, are complete when required and the costs are no more than planned unless changes are accepted and agreed upon at the appropriate management level.

The APT CDR will be used as the basis for establishing the initial technical scope, schedule, and cost APT Baselines. Proposed changes to Project baselines use the BCP process discussed in detail in the APT Project Controls Policy Manual. Change control thresholds are shown in Table 2 and are addressed in the policy manual.

Technical Baseline: The major APT technical performance criteria represent the top-level system requirements that must be achieved to satisfy the APT Mission requirements. The requirements were established in December 1995 with the approval of CD-1, Approval of Mission Need and are described in Section 1.3.1.

As the design progresses, the FDD, SDDs, interface Control Documents, and design information in the form of top-level drawings, calculations, and specifications will be prepared and incorporated into the APT baseline. In addition, key ES\&H documents such as Programmatic Environmental Impact 
Statement (EIS) and the Preliminary Safety Analysis Report (PSAR) will be established formally.

Cost Baseline: The APT Facility Final CDR cost estimate with associated profiles of budget authorization and outlay forms the basis for the APT cost baseline. This baseline is described in Sections 1.3.3 and 6.1 and will be updated when preliminary design is completed. The Construction Project Data Sheets contain the TPC, including TEC and Other Project Cost (OPC) estimates.

Schedule Baseline: The Integrated Project Schedule (IPS) in the form of timephased logic diagrams and the key milestone listings in the APT Facility Final CDR, form the basis for the APT schedule baseline. The schedule milestone baseline is described in Sections 1.3.2 and 5.2 and is based on the schedule data in the CDR.

Table 2. Project Baselines Scope, Cost and Schedule Change Control Authorities

\begin{tabular}{|c|c|c|c|}
\hline & Acquisition Executive & Program Manager & Project Director \\
\hline BASELINE & LEVEL 0 & LEVEL 1 & LEVEL 2 \\
\hline $\begin{array}{l}\text { Technical } \\
\text { (Scope) }\end{array}$ & $\begin{array}{l}\text { Build piant to produce } \\
3 \mathrm{KG} \text { of Tritium per } \\
\text { year }\end{array}$ & $\begin{array}{l}\text { - Project Execution Plan } \\
\text { - Core Technology Plan - } \\
\text { Table } 4 \\
\text { - Facility Design Description - } \\
\text { Section } 1\end{array}$ & $\begin{array}{l}\text { - Implementing Plans } \\
\text { - Core Technology Plan - } \\
\text { Tables 6-11, 14-19, } 21 \text { and } \\
22 \\
\text { - Facility Design Description } \\
\text { - Work Breakdown Structure } \\
\text { Level } 2\end{array}$ \\
\hline Cost & $\begin{array}{l}\text { - Total Project Cost } \\
\text { (TPC) } \\
\text { - Total Estimated Cost } \\
\text { (TEC) } \\
\text { - Other Project Costs } \\
\text { (OPC) - (>50M each) }\end{array}$ & $\begin{array}{l}\text { - TPC, TEC, OPC - (\$5M - } \\
\$ 50 M \text { each) } \\
\text { - Annual Funding Profile } \\
\text { - Contingency Allocation - } \\
>\$ 5 M \\
\text { - Core Technology Plan - Total } \\
\text { ED\&D cost in Table } 2\end{array}$ & $\begin{array}{l}\text { - TPC, TEC, OPC - (\$5M } \\
\text { each) } \\
\text { - TEC, OPC Profile by } \\
\text { Participant } \\
\text { - Contingency Allocation } \\
<\$ 5 M \\
\text { - Management Reserve } \\
(>\$ 500 K)\end{array}$ \\
\hline Schedule & $\begin{array}{l}\text { - Level } 0 \text { Milestones (>6 } \\
\text { mo. change) }\end{array}$ & $\begin{array}{l}\text { - Level } 0 \text { Milestones (<6 mo. } \\
\text { change) } \\
\text { - Level } 1 \text { Milestones }\end{array}$ & - Level 2 Milestones \\
\hline
\end{tabular}




\subsubsection{Change, Configuration, and Contingency Control}

Establishing and maintaining baselines are the most important aspects of project control. Changes to baselines will be vigilantly governed to avoid loss of control and distortion in performance reporting. Baseline control is a management tool to ensure limits and requirements are understood and changed by management agreement only.

The purpose of the Project Change Control System is to assure:

- Cost, schedule and technical impacts of proposed changes are developed and considered by all appropriate parties.

- Collected evaluations are considered in approving or rejecting the proposed changes.

- Appropriate parties are informed of proposed changes and change disposition prior to change(s) being implemented.

- Baseline documentation is controlled and updated as appropriate to reflect approved changes.

Baseline Change Control: Change Control Boards (CCBs) will be established at various levels to approve, disapprove, or endorse such as recommending approval to a higher-level CCB all proposed changes exceeding established thresholds.

Approved changes affecting Level 0 baselines will be dispositioned by the acquisition executive (the DOE Secretary of Energy or designee). Level 1 baseline changes will be dispositioned by the DOE APT Program Manager and Level 2 changes by the APT Project Director. The BCC process and the Change Control Board hierarchy is discussed in the APT Project Controls Policy Manual. Each lower-level CCB will endorse all proposed changes to be considered by the next higher-level board. This process ensures correct oversight of all proposed changes, which can originate at any level in the project, but which must be fully evaluated at Level 3 or above as appropriate to the magnitude of the change. The thresholds determine the appropriate management approval level.

Membership on the CCB will be at the discretion of the respective board chair. Authority and responsibilities of each board are to be defined in its decisionmaking charter. The DOE Level 0 and Level 1 CCB Chairs will maintain complete decision-making authority. The APT Project Director's Office has established a CCB to review Level 2 BCPs. All BCP requests will be processed in accordance with the change control procedure of the principal participant. 
The cost and schedule process is discussed in detail in the APT Project Controls Policy Manual. Levels 0 , Level 1 and Level 2 Change Control Authorities are shown in Table 2.

Configuration Control: The APT Project will control the project technical documents and corresponding end-item configuration through the process of issuing, reviewing and approving changes. These are the primary change processes for project documents and are central to the APT Configuration Control System, which will ensure the project documents correctly reflect the approved design. The Configuration Control System is described in the APT Configuration Management Plan and the implementing project procedures. These plans and procedures will ensure the technical baseline and corresponding end-item configuration is controlled, documented and verified.

Contingency Control: Project contingency is the planned funds identified in the Plant-and-Capital-Equipment-funded APT Total Estimated Cost activity. Such funds cover unplanned but in-scope problems. Contingency was first established in the Conceptual Design process and documented in the APT CDR. Contingency requirements will be updated after P\&FD. For the APT Project, use of project contingency will be controlled by the PDO. A master change control log will be maintained by the PDO to record each allocation. Contingency will be monitored and controlled on a total project basis.

\subsubsection{Federal Budgeting}

APT funding requests are prepared and submitted in accordance with the DOE annual budget request process. Such requests will be included as part of the 5100.3, Field Budget Process; DOE 5100.5, Office of Management and Budget Process; DOE 5100.6, Congressional Budget Review and Guidance letters issued by the DOE Chief Financial Officer for the Corporate Budget Review Process.

The APT Project Director will issue to all APT participants annual budget planning guidance which is consistent and approved by the APT Program Manager. This guidance will include a brief discussion of the proposed scope of work for the coming year, identification of current year scope and funds to be rolled-over into the next year and budget targets by participant. Participants will then prepare detailed Work Packages in accordance with the project controls policy manual.

Funds will be distributed in accordance with the Approved Funding Plan policies and procedures. All appropriate documentation will be prepared and submitted by the APT HQ Budget Officer and transmitted to the participant via the Work Authorization/Prime Contract Modification process. This process authorizes the participants to perform work. 


\subsubsection{Performance Measurement and Reporting}

Project control and reporting requirements are outlined herein and are based on the Life-Cycle Asset Management DOE Order 430.1, the draft of Secretarial Officers With Program Responsibilities-Project Management Policy, and the Joint Program Office Direction on Project Management. The requirements will provide a graded approach to project management. The approach minimizes overall project cost and schedule risk. The Project Control System is closely integrated with the BCC process and will provide the required statusing and cost and schedule variance analyses and trend analyses for each specified reporting period. The APT Project will require an Integrated Project Control System which can provide effective planning and reporting, as well as day-to-day management. The System must include attributes to:

- Separate the work scope into tasks including time-phased budgets and resource plans.

- Measure and report actual costs, cost variances and commitments against the approved task plans and established baselines and performs trending analyses .

- Monitor and report schedule progress and schedule variances against approved task plans and established baselines and perform trending analyses.

- Prepare Milestone reports of planned versus actuals by WBS element.

- Generate and maintain the cost and schedule baseline estimates for the project.

- Forecast future funding requirements.

- Provide the basis for project budget submittals and for budget validations.

- Monitor and control procurement and contracting activities and commitments.

The APT Project Controls Policy Manual provides details of the APT project management and reporting requirements.

\subsubsection{DOE Reports and Reviews}

Project Status Reports: Table 3 lists the required DOE APT Project Status Reports. These reports are integral to the APT Project technical scope, schedule, cost tracking and reporting processes.

Table 3. Required Project Controls Reports 


\begin{tabular}{|llll|}
\hline REPORT & DESCRIPTION & SUBMITTED BY & SUBMITTED TO \\
\hline \hline Monthly Status & $\begin{array}{l}\text { Integrated project status } \\
\text { and monthly performance } \\
\text { report, including cost and } \\
\text { schedule roll-up for total } \\
\text { project }\end{array}$ & PDO & DOE \\
Monthly Performance & $\begin{array}{l}\text { Submitted by project } \\
\text { participants. Uses standard } \\
\text { reporting formats. }\end{array}$ & participants & PDO \\
Weekly Highlight & $\begin{array}{l}\text { Integrated project activity } \\
\text { highlight report }\end{array}$ & PDO & DOE \\
Annual & $\begin{array}{l}\text { Integrated project } \\
\text { performance report for year }\end{array}$ & PDO & DOE \\
\hline
\end{tabular}

Independent Project Reviews: The APT External Review Committee established by the PDO will be the organization responsible for providing peer review and guidance. In addition, several technical review groups associated with the APT project report to individual project organizations. Other special reviews, such as the ongoing public review of the impact of APT on nonproliferation will be defined by Congress or the DOE as required.

Other APT Reviews: Additional reviews may include Independent Cost Estimates, external cost, system compliance, budget validation, baseline validation, peer reviews and various design reviews. When possible, DOE reviews will be combined or performed concurrently with PDO reviews/audits to minimize the impact on the day-to-day activities of the APT Project.

\subsubsection{Quality Assurance}

The predominant objective of a QA Management System for the APT Project is to provide adequate confidence that the Project Mission and Objectives can be achieved by the items, services and processes of the facility. The Project QA Management System will be developed and implemented consistent with the criteria contained in 10 CFR 830.120 , Quality and with DOE Order 5700.6C, Quality Assurance. Documentation of the Program will be developed as a series of Quality Assurance Program Plans (QAPP), of which the APT Project Office QAPP will be dominant. The QAPP of other participating organizations, will also reflect appropriate compliance with the regulation, the DOE order and the QAPP of the APT Project Office. 
The QA activities on the APT Project will be applied in a graded manner consistent with the rationale provided in DOE Standard Preparation Guide for US DOE Nonreactor Nuclear Facility Safety Analysis Reports (DOE-STD-300994). This Standard indicates the systems, structures and components (SSCs) identified as containing the potential for nuclear hazards. The SSCs are grouped into two classifications:

Safety Class: Those SSCs where accident analysis indicate a need to prevent accident consequences from exceeding Evaluation Guidelines. Safety Class designation has traditionally been reserved for SSCs needed to protect the public. This designation carries with it the most stringent requirements such as enhanced inspecting, testing and maintenance and special Instrumentation and Control Systems.

Safety Significant: Those SSCs of particular importance to in depth defense or worker safety as determined by hazard analyses. Control of Safety-Significant SSCs does not require meeting the level of stringency associated with SafetyClass SSCs.

Other Classifications: The other classes are determined first at a systems level and then for the SSCs comprising the system. The determinations are based on a formal processes including performing Hazards and Safety Analyses, defining the required safety system functions and determining the importance of systems and sub-systems. The same will also be determined for the component SSCs in assuring the required safety system functions will be performed when scheduled. This process is defined in more detail in Section 7.9.1, Facility Safety.

In addition to being in one of the listed safety classifications, an SSC is evaluated in terms of its importance to production. Based on this evaluation, the SSC may be classified into one of the following classifications:

Production Support: Those SSCs necessary to support the operation of the facility and select environmental monitoring and Emergency Response Plan communication devices.

General Services: These SSCs are not classed as Safety-Class, SafetySignificant or Production Support.

The process for determining the importance of an SSC to production is described in Section 7.8, RAMI. In addition to considering the probability of an event occurrence such as SSC failure, the consequences of the event are also considered. Therefore, even though a certain SSC failure may have a low probability of occurring, if it has a high consequence such as extending production down time, it may be classified as a Production Support SSC. 
Within each classification, applying QA controls, verifying actions, and documenting each will be determined through evaluating such factors as:

- Relative importance to safety and S\&S.

- Magnitude of risk associated with identified hazards.

- Complexity of the design, manufacture, assembly or use.

- Past experience with the component or similar components.

- Impact of failure of mission and objectives.

\subsubsection{Design Authority}

Design Authority (DA) is a critical facet of the DOE program for ensuring a functioning APT plant. The DOE is the overall DA, and as such, is responsible for ensuring the design is appropriate, functions as it should and is adequate. Additionally, the DOE is using lessons learned and processes from other weapons programs such as life cycle responsibility and from the commercial industry such as technical accountability. The DOE has assigned DA responsibility to the APT PDO, who in turn has assigned the DA to the TPO at LANL.

To ensure design adequacy, technical accuracy and appropriateness, the DA has the following responsibilities:

- Establish the initial and the prototype baseline design and the physical, functional and operational requirements for assigned SSCs.

- Control these requirements in appropriate sections of the APT FDD and SDDs.

- Review technical baseline documentation for adequacy and acceptability.

- Identify and address technical discrepancies and potential adverse effects.

- Evaluate proposed modifications to the technical baseline for APT SSCs and recommend Project Office disposition.

- Revise the requirements through the change control process if a proposed modification results in a change to the physical, functional and operational requirements,.

- Review and recommend disposition of non-conformances that impact the physical, functional and operational requirements.

- Provide technical advice to DOE.

- Provide operations assistance to the plant M\&O Contractor for the life 
of the facility.

- Evaluate the acceptability of, and changes to, the design of a SSC and its technical baseline.

This TPO responsibility will be executed as follows:

- Establish the initial baseline design and physical, functional, and operational requirements for assigned SSCs. These requirements will be documented and controlled in the appropriate sections of the APT FDD and SDDs .

- Review technical baseline documentation for adequacy and acceptability. The review will identify and address technical discrepancies and potential adverse effects.

- Evaluate proposed modifications to the technical baseline for assigned SSCs and will recommend disposition. If the proposed modification results in a change to the physical, functional, and operational requirements, a revision will be made through the change control process with approval at a level consistent with this PEP.

- Review and recommend disposition of the resolution of nonconformances impacting physical, functional and operational requirements.

\section{APT Acquisition Strategy}

The procurement and acquisition strategy to be employed for the APT Project is founded on principles that have been used successfully on other projects of similar nature. These principles are:

- Maximize the use of fixed-price, competitive procurements.

- Use the negotiated procurement process as described in the Federal Acquisition Regulation.

- Minimize the use of cost-type contracts or sole source procurements.

- Allow, as permitted, for award of purchase orders under General Service Agency (GSA) agreements.

- Allow for local field procurements which permit local economies to maximize involvement in the project.

- Encourage the use of small, women-owned, small disadvantaged and minority businesses. 
- Use formal procedures which comply with the FAR, DOE Acquisition Regulations and which have been approved by appropriate authorities.

- Perform aggressive searches for useful government surplus equipment during the ED\&D Phase.

The APT Project will also actively endeavor to seek out and apply best commercial and government practices to acquisitions and procurements. An example is the use of expert independent review teams in evaluating the Prime contract awarded to BREI. An outside team of expert evaluated the project practices against the best current government and business practices and provided recommendations based on those reviews. Specific initiatives being considered for implementation based on reviews already complete include:

- Pursuing full capital funding rather than incremental funding by fiscal year, beginning in the FY99 Budget Cycle.

- Implementing common performance measures and incentives for all team members.

- Ensuring the project organization performs as a unified team.

- Using strategic sourceing practices.

- Using performance specifications for equipment purchases.

An Acquisition Plan will be developed which describes the plans for procuring all equipment, materials and construction services necessary to design, equip, construct and commission the APT plant. The exception is items designated as Government Furnished Equipment. Items designated as Government Furnished Equipment will be procured via processes based on the principles discussed above.

The Acquisition Plan will describe the process for selecting subcontractors, processing procurement documents, evaluating proposals, and establishing selection criteria. It will also describe the overall approach to acquisition scheduling, organization, data management and cost control. It will also contain schedules for the major procurements based on the IPS.

To ensure a commonality of processes and approaches and to coordinate with the IPS and other needs, a dedicated procurement team will be established. The Team will be responsible for as many of the APT acquisitions as practicable. However, all participating organizations will make independent procurements as needed in accordance with individual contracts or cooperative agreements. The contracts or agreements must be in effect between the organization and DOE and each must meet the APT QA Program Plan provisions. 


\section{Project Schedule}

The IPS defines the technical elements of the APT from engineering development and demonstration through P\&FD, construction and OT\&C.

The APT Project schedule consists of a hierarchy of schedules generated from an IPS included in a data base managed at Level 2 of the WBS. The IPS can be summarized to create the Project Master Schedule or expanded to detailed schedules used for time-phasing work by individual task managers. Each of the lower tier schedules is compatible with the Project Master Schedule, with key milestones traceable from the top level schedule to the lower tier schedules.

The APT Integrated Project Schedule was developed by:

- Defining critical milestones, ED\&D deliverables and associated interface points.

- Reviewing and analyzing the schedule logic, sequence and the ability to construct or manufacture all the elements of the plant.

- Developing a coordinated, comprehensive contract packaging strategy that maximizes design deliverables and minimizes schedule delays.

- Defining critical paths throughout the program which focus project management attention on critical and schedule impacting activities.

- Assessing schedule risks and developing risk mitigation strategies and recovery plans.

The APT Project scheduling hierarchy is as follows:

- Levels 0, 1 and 2 Milestones

- Project Summary Schedule

- Detail Activity Schedule

\subsection{Schedule Decision Points and Status}

The following decision points have been established for the APT project:

- Critical Decision 1 (CD-1): Approve Mission Need; Completed December 1995

- Critical Decision. 2 (CD-2): Approve Project Baseline, July 1997

- Critical Decision 3 (CD-3): Approve Start of Construction, October 1998 
- Critical Decision 4 (CD-4): Approve Plant Acceptance, June 2007.

\section{Project Cost}

The APT Project cost estimate consists of the following elements:

- Total Estimated Cost: The TEC funds activities include P\&FD, systems engineering, procurement, construction, construction management and project management activities.

- Other Project Costs: The OPC funds activities include ED\&D, Conceptual Design, ES\&H, and OT\&C activities.

- Total Project Cost: The TPC includes escalation and contingency and is $\$ 4,508.6 \mathrm{M}$. A breakout of these costs is shown in Table 4.

Table 4. Total Program Cost Summary

\begin{tabular}{|l|r|}
\hline Cost Type & 1997 \$ in Millions \\
\hline \hline Total Estimated Cost (TEC) & $2,296.3$ \\
\hline Other Project Cost (OPC) & 827.2 \\
\hline Project Contingency & 858.9 \\
\hline Escalation & 526.2 \\
\hline Total Project Cost (TPC) & $\mathbf{4 , 5 0 8 . 6}$ \\
\hline
\end{tabular}

\section{Engineering Principles and Processes}

The requirements of this PEP and the referenced documents will be incorporated into the APT Project through a series of formal programs. Plans will be prepared to detail the requirements and related principles and processes that will provide the bases of implementing procedures.

These Program Plans are listed below and are summarized in the following subsections:

- Core Technology Plan (Section 7.1)

- Systems Engineering Management Plan (Section 7.2)

- Configuration Management Plan (Section 7.3)

- Quality Assurance Program Plan (Section 7.4) 
- Value Engineering Plan (Section 7.5)

- Environment, Safety and Health Plan (Section 7.6)

- Safety Implementation Plan (Section 7.6.1)

- Worker Protection Plan (Section 7.6.2)

- Environmental Plan (Section 7.6.3)

- Environmental Impact Statement Management Plan (Section 7.6.4)

- Waste Management Plan (Section 7.6.5)

- Environmental Permitting and Compliance Plan (Section 7.6.6)

- Public Participation Plan (Section 7.6.7)

- Safeguards and Security Plan (Section 7.7)

The Acquisition Plan is discussed in Section 4 of this document. As the project progresses to subsequent phases as discussed in Section 2.3, additional processes will be added as required.

\subsection{Core Technology Plan}

The Core Technology Plan describes the ED\&D Program under which activities support conceptual, P\&FD APT plant design. Some of the Plan specifics are discussed in Section 2.2.

The focus of the ED\&D Program is derived from the emphasis placed by the DOE on satisfying specific design data needs which result in well-defined APT plant environments. The activities and the associated implementing schedules will be coordinated and integrated with the requirements of the APT plant design the activities support.

\subsection{Systems Engineering Management}

A Systems Engineering Management Plan will be developed and followed to ensure the APT design is focused on meeting the DOE requirements and the design basis is documented. To meet these requirements, systems interfaces will be identified, tracked and documented. The interfaces of systems and functional equipment requirements will be optimized. The systems engineering tasks include:

- Functional Performance Analysis including defining systems performance requirements and performing requirement allocation analysis at system and subsystem level

- Functional Analysis including identifying and tracking functional interfaces, performing and evaluating systems performance modeling

- Design evaluation support.

The systems engineering process is illustrated in Figure 5. 


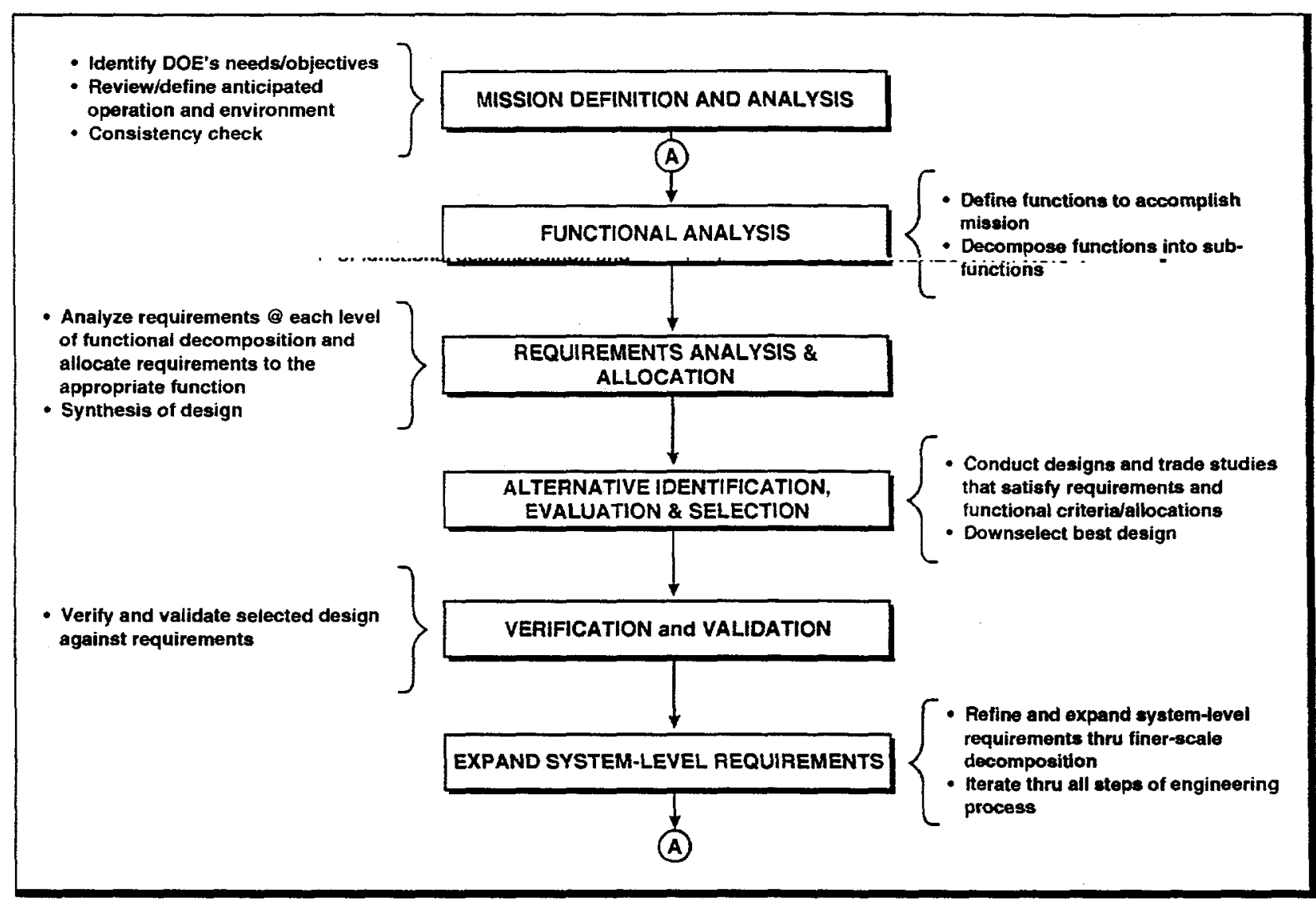

Figure 5. Systems Engineering Process

\subsection{Configuration Management}

For the APT Project to be completed successfully, all participants must be provided with accurate, up-to-date information at any given point in the project life cycle. To achieve this, a Configuration Management Program will be established. The Program will use a system by which technical information is documented and changes to the documents are controlled. This integrated management process, described in detail in the APT CMP, will provide the means to:

- Identify and control the documents which define the configuration baseline for the plant

- Provide a systematic method for managing approved changes to the technical baseline and ensuring the changes are correctly documented 
- Provide verification that end-item configuration conforms to the technical baseline.

The DOE Life Cycle Asset Management, Good Practice Guide, GPG-FM-012, Configuration and Data Management, and the SRS Configuration Management Strategic Implementation Plan, WSRC-RP-94-0766, as amended, will be used as the basis for developing the APT CMP.

\subsection{Quality Assurance Program Plan}

The APT PDO Quality Assurance Program Plan documents the PDO commitment to manage all work on the project in a manner prescribed in applicable Federal Regulations and DOE Orders. The plan explains the application of quality management to specific activities to be performed on the project. The QAPP will be supported by a series of implementing procedures. An amplification of the basis of the QAPP for APT is located in Section 3.3.6 of this document.

\subsection{Value Engineering Plan}

A Value Engineering Plan will be prepared to define the process in which improvements to the design and construction of the facility will be proposed, evaluated and accepted. The process will be consistent with established guidelines which facilitate developing, reviewing, accepting and implementing Value Engineering Change Proposals (VECPs).

The VECPs will be encouraged and expedited in all circumstances. The process is essential to achieve the greatest cost savings to the Project without sacrificing mission capability, environmental considerations or employee and/or public health and safety.

The VECP requirements and basis for sharing in cost savings are defined in the FAR Paragraph 248.1 and have been incorporated by reference into contracts for the APT participants.

\subsection{Constructibility and Decommissioning Facilitation}

Construction viewpoints and requirements (the "constructibility process") will be considered as a regular and routine part of design management and review for the APT Project. The principal objectives of the process are to enhance the ability to construct the facility efficiently and to assist in meeting project requirements for safety, quality, cost and schedule. As design documents are published in various stages and revisions, construction management personnel 
will review the documents and offer constructibility comments. Such comments will be recorded and dispositioned in the same manner as other design review comments.

Measures to facilitate and reduce costs during decommissioning will also be considered as design documents reviewed. Constructibility measures and factors and decommissioning facilitation features will be considered in Value Engineering Assessments and in Engineering Trade Studies.

\subsection{Environment, Safety, and Health Planning}

The planning for Environmental, Safety and Health issues will be driven by regulatory requirements. The plans to meet the requirements will include the drivers, assumptions, schedules and milestones necessary to meet each regulatory requirement. Collectively, the Plans will address facility safety, worker protection, environmental compliance, pollution prevention, and waste minimization for the APT Project.

All plans will be assessed periodically to incorporate program and regulatory changes and to develop detailed strategies as the project requirements develop. Sections 7.6.1 through 7.6.7

\subsubsection{Safety Implementation Plan}

The purpose of the Safety Program is to ensure the facilities will provide protection for the workers, the public and the environment. The APT Safety Implementation Plan will be developed to define the process by which the Safety Program will be accomplished. It will include preparing safety documents following a hazard based approach. The methodology to be used will provide a systematic approach to developing safety documentation, consisting of the following steps:

- Hazard Identification - Hazardous energy sources, radiological hazards, non-radiological toxic hazardous materials will be identified. Additionally, potential initiators for release of hazards such as natural phenomena hazards or external events will be identified. These hazards, if released, might place a facility, an operation, workers or the public in jeopardy.

- Hazard Analysis - An evaluation of the identified hazards relative to possible events and their causes will be performed. Such analyses include release of the hazard or the consequences caused by the hazard itself, such as for energy sources. Available features for mitigating and preventing each event are identified. The consequences of each event will be qualitatively evaluated and the 
events will be grouped based on hazard level and potential event frequency.

- Preliminary Functional Classification - The SSCs which provide the required worker safety and defense-in-depth safety functions will be identified. Additionally, the classification will provide preliminary selection of the SSCs and thereby provide a required safety function.

- Accident Analysis - Event scenarios and analyses of specific events will be developed. These will verify that the selected SSC safety functions will prevent or mitigate an events and therefore will meet established safety criteria.

- Final Functional Classification - A final selection of SSCs credited in the safety analysis will be performed. The analysis will ensure the required safety functions are provided.

- Technical Safety Requirement - The requirement will ensure the safety functions are maintained and the safety envelope for the facility is protected.

- Safety Analysis Report - The Report will provides the formal documentation of the safety case for the facility.

This methodology uses a graded approach to document the safety basis of the facility. Therefore, it is the primary tool for integrating APT safety documentation and for facilitating the development of a well documented and defensible safety case for the project.

The project will use FDD and SDDs to document and control APT requirements including safety requirements and to define the project technical baseline as discussed in Section 5.1. Therefore, safety is being integrated into the design process at all levels. The safety requirements imposed on the Project are based on DOE regulations, and will be developed by the use of DOE rules and regulations relative to safety or safety documentation. The specifics may change if the recommendations of the Advisory Committee on External Regulation of DOE Nuclear Facilities are implemented. The fundamental requirements are expected to be similar regardless of the regulator.

Specific expectations relating to demonstrating fundamental requirements being met may vary depending on the regulator. At this time, the project is required to meet DOE requirements. Compliance with these requirements will form the basis for the APT safety case. Interfaces with oversight groups and regulatory agencies, such as the Defense Nuclear Facility Safety Board and the State of SC will be developed to obtain input for developing requirements and compliance activities for the APT. 


\subsubsection{Worker Protection Plan}

The basic regulations pertaining to worker safety are contained in Occupational Safety and Health Administration (OSHA) requirements that form the bases on which all other worker safety considerations are built. In addition, the SRS maintains a Process Safety Management Program that accounts for all the elements of the OSHA Process Safety Management Program. Both OSHA and the Process Safety Management requirements (as incorporated into the SRS practices and procedures) will be taken into account. These elements will become the basis for a Worker Protection Plan. The APT Project will classify worker functions as safety significant with appropriate protection specified within the Technical Safety Requirements.

\subsubsection{Environmental Planning}

For the ED\&D efforts, an Environmental Assessment (EA) for the LEDA at Technical Area-53, at LANL, (DOE-EA-1147) was performed. The EA was performed to evaluate the DOE plan to design, build and test critical prototypical components of the accelerator system for tritium production. A Finding of No Significant Impact for the LEDA EA is dated April 1, 1996. The testing and experimental work to be performed at LANL will be completed based on the Laboratory requirements for environmental compliance and site environmental mitigation plans as opposed to the APT plant which will be constructed at the SRS and meet EPA and SCDHEC requirements.

For the APT plant, elements of environmental planning efforts will include the Plans itemized below and discussed in Sections 7.6.4 through 7.6.7:

- Environmental Impact Statement (EIS) Management Plan

- Waste Management Plans

- Environmental Permitting and Compliance Plans

\subsubsection{Environmental Impact Statement Management Plan}

An ElS Management Plan will be developed to provide for controlling and conducting an integrated effort to support DOE-Savannah River in preparing the APT EIS. The EIS is part of the strategy for APT to meet existing requirements of the EPA and the State of South Carolina. The EIS will be reviewed at appropriate intervals to ensure its continued adequacy. Use of the EIS Management Plan will facilitate implementing critical EIS elements such as data management, document preparation and review, correspondence and commitment tracking, team communication and integration, project management, and maintaining interim and end-product quality. 


\subsubsection{Waste Management Plan}

The Waste Management Plan (WMP) details the requirements and issues specific to the APT for design considerations, construction, and operation. The WMP evaluates the various waste streams that will be generated by the APT, addresses the key issues regarding the waste stream dispensation and identifies the SRS interfaces for each. The WMP outlines the requirements for waste characterization and certification and defines an approach for waste minimization opportunities. The WMP also identifies the regulatory drivers for waste management requirements.

\subsubsection{Environmental Permitting and Compliance Plan}

The Environmental Permitting and Compliance Plan is intended to enumerate the environmental permits necessary for constructing and operating the APT and associated BOP infrastructure at the SRS. The Environmental Permitting and Compliance Plan addresses all applicable EPA, SCDHEC, and DOE rules, regulations and orders. The Plan includes a list of assumptions and a two-level hierarchy consisting of a detailed schedule and a summary schedule which will be closely coordinated with the overall project schedule.

In addition, other specific Environmental Plans will be developed including a Pre Operational Environmental Monitoring Plan and a Mitigation Action Plan for commitments in the EIS, if required.

Prior to construction and operation, the APT facilities will require appropriate environmental permits, including but not limited to;

- National Pollution Discharge Elimination System permit for liquid effluent outfalls.

- National Emission Standards for Hazardous Air Pollutants permit radiological emissions to the air.

- Clean Air Act Title V Permit for non-radiological air emissions.

- Resource Conservation and Recovery Act permits for hazardous waste storage, treatment or disposal activities.

- Various construction and operating permits including permits obtained from the SCDHEC and the EPA through application and, where appropriate, hearing processes.

- The EIS Record of Decision which includes decisions regarding purpose, need, and technical and site alternatives. A positive decision on the project-specific analysis of the environmental impacts of APT construction and operations will allow finalizing design and initiating site preparation and building excavation. 
- After the National Environmental Protection Agency (NEPA) determination is complete, the environmental permit required for construction will be obtained.

- Prior to plant operation beginning, environmental permits required for plant operation will be obtained.

\subsubsection{Public Participation Plan}

The Public Participation Plan (PPP) is a means to ensure meaningful and early public input is received, considered and a response provided with regard to DOE activities. The PPP identifies public participation methods that will be integrated into the development of the APT. The APT PPP fully supports DOE guidance policy in which public involvement is a fundamental component of the DOE Program operations, planning activities and decision-making. The PPP also supports policy and guidance as specified by DOE-Savannah River public participation procedures.

\subsection{Safeguards and Security}

The APT Project involves data and special equipment which will require specific safeguards. The project itself represents a large investment of government funds in assets that must be protected. The FDD and the SDDs contain guidance for the security-system design requirements. A Safeguards and Security Plan will be prepared during preliminary design and will be updated prior to the ORR. The Plan will describe the DOE requirements as well as the project compliance of the APT design such as access control, vaults, secure transfer lines and other S\&S issues. It will also include the implementing administrative procedures. The Plan will describe the SRS Security Organization and interface with the APT Project Security Team. Issues relating to the transparency of experimentation by the user community and international collaboration will be addressed in the APT S\&S Plan. 


\section{Acronyms and Definitions}

$\begin{array}{ll}{ }^{3} \mathrm{He} & \text { Helium 3 } \\ \text { APT } & \text { Accelerator Production of Tritium } \\ \text { CCB } & \text { Change Control Board } \\ \text { BCP } & \text { Baseline Change Proposal } \\ \text { BOP } & \text { Balance of Plant } \\ \text { BREI } & \text { Burns and Roe Enterprises, Inc. } \\ \text { CD } & \text { Critical Decision } \\ \text { COR } & \text { Contract Officer Representative } \\ \text { CDR } & \text { Conceptual Design Report } \\ \text { DOE } & \text { Department of Energy } \\ \text { DOE-HQ } & \text { Department of Energy - Headquarters } \\ \text { DPD } & \text { Deputy Project Director } \\ \text { EA } & \text { Environmental Assessment } \\ \text { ED\&D } & \text { Engineering Development and Demonstration } \\ \text { EIS } & \text { Environmental Impact Statement } \\ \text { EPA } & \text { Environmental Protection Agency } \\ \text { ES\&H } & \text { Environmental Safety and Health } \\ \text { FAR } & \text { Federal Acquisition Regulation } \\ \text { FDD } & \text { Facility Design Description } \\ \text { FY } & \text { Fiscal Year } \\ \text { GA } & \text { General Atomics } \\ \text { GFE } & \text { Government Furnished Equipment } \\ \text { IPS } & \text { Integrated Project Schedule } \\ \text { LANL } & \text { Los Alamos National Laboratory } \\ \text { LCC } & \text { Life Cycle Costs } \\ \text { LEDA } & \text { Low Energy Demonstration Accelerator } \\ \text { Linac } & \text { megawatt } \\ \text { M\&O } & \text { Mccelerator } \\ \text { MeV } & \text { MW }\end{array}$




$\begin{array}{ll}\text { MWe } & \text { Megawatts Electrical } \\ \text { NEPA } & \text { National Environmental Protection Agency } \\ \text { O\&M } & \text { Operations and Maintenance } \\ \text { OPC } & \text { Other Project Costs } \\ \text { OPO } & \text { Operations Project Office } \\ \text { ORR } & \text { Operational Readiness Review } \\ \text { OSHA } & \text { Occupational Safety and Health Administration } \\ \text { OT\&C } & \text { Operational Testing and Commissioning } \\ \text { P\&FD } & \text { Preliminary and Final Design } \\ \text { PDO } & \text { Project Director's Office } \\ \text { PEP } & \text { Project Execution Plan } \\ \text { PPO } & \text { Plant Project Office } \\ \text { PPP } & \text { Public Participation Plan } \\ \text { PSAR } & \text { Preliminary Safety Analysis Report } \\ \text { QAPP } & \text { Quality Assessment Program Plan } \\ \text { RAMI } & \text { Reliability, Availability, Maintainability and Inspectability } \\ \text { RF } & \text { Radio Frequency } \\ \text { S\&S } & \text { Safeguards and Security } \\ \text { SCDHEC } & \text { South Carolina Department of Health and Environmental Control } \\ \text { SDD } & \text { System Design Description } \\ \text { SRS } & \text { Savannah River Site } \\ \text { SSC } & \text { Systems, Structures and Components } \\ \text { T/B } & \text { Target/Blanket } \\ \text { TEC } & \text { Total Estimated Cost } \\ \text { TPC } & \text { Total Project Cost } \\ \text { TPO } & \text { Technology Project Office } \\ \text { TSF } & \text { Tritium Separation Facility } \\ \text { VECP } & \text { Value Engineering Change Proposal } \\ \text { WBS } & \text { Work Breakdown Structure } \\ \text { WMP } & \text { Waste Management Plan } \\ \text { WSRC } & \text { Westinghouse Savannah River Company } \\ & \end{array}$

